\title{
A Qualitative Study of African-American Job Satisfaction in a Scientific/Technical Research Environment
}

Cheryl D. Krossa

(M.A. Thesis) 


\section{DISCLAIMER}

This document was prepared as an account of work sponsored by an agency of the United States Government. Neither the United States Government nor the University of California nor any of their employees, makes any warranty, express or implied, or assumes any legal liability or responsibility for the accuracy, completeness, or usefulness of any information, apparatus, product, or process disclosed, or represents that its use would not infringe privately owned rights. Reference herein to any specific commercial product, process, or service by trade name, trademark, manufacturer, or otherwise, does not necessarily constitute or imply its endorsement, recommendation, or favoring by the United States Government or the University of California. The views and opinions of authors expressed herein do not necessarily state or reflect those of the United States Government or the University of California, and shall not be used for advertising or product endorsement purposes.

This report has been reproduced directly from the best available copy.

Available to DOE and DOE contractors from the Office of Scientific and Technical Information P.O. Box 62, Oak Ridge, TN 37831

Prices available from (615) 576-8401, FTS 626-8401

Available to the public from the National Technical Information Service

U.S. Department of Commerce 5285 Port Royal Rd., Springfield, VA 22161 
UCRL-LR-126706

Distribution Category UC-700

\title{
A Qualitative Study of African-American Job Satisfaction in a Scientific/Technical Research Environment
}

\author{
Cheryl D. Krossa \\ (M.A. Thesis)
}

September 1996

\section{LAWRENCE LIVERMORE NATIONAL LABORATORY University of California • Livermore, California • 94551}




\title{
A Qualitative Study of African-American Job Satisfaction in a Scientific/Technical Research Environment
}

This Directed Research was written by

\author{
Cheryl Delemos Krossa
}

This Directed Research was written under the guidelines of the Faculty Advisory Committee, and approved by all its members, has been accepted in partial fulfillment of the requirements of:

\author{
Master of \\ Human Resources and Organization Development \\ at the \\ The University of San Francisco
}

Research Committee:

Content Advisor

Methodologist

Director of Research

Date

Dean 
A Qualitative Study of African-American Job Satisfaction in a Scientific/Technical Research Environment

A Directed Research Submitted

by

Cheryl Delemos Krossa

In Partial Fulfillment of the Requirements

For the Degree of

Master of

Human Resources and Organization Development

The University of San Francisco

September 18, 1996 


\section{TABLE OF CONTENTS}

Abstract................................................................. ii

Vita Autoris........................................................................

Acknowledgements.......................................................... iv

List of Tables......................................................................... v

List of Appendices.............................................................. v vii

Chapter One: Introduction................................................... 1

Chapter Two: Review of Related Literature........................... 10

Chapter Three: Methodology................................................. 20

Chapter Four: Findings.......................................................... 31

Chapter Five: Summary and Conclusions............................. 55

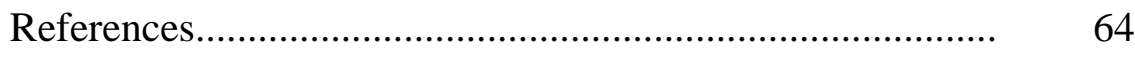

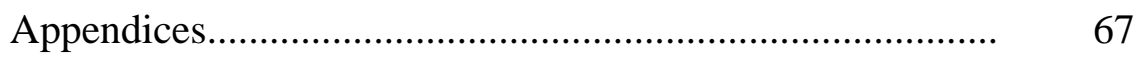




\begin{abstract}
The purpose of this study was to begin to develop an answer to the question, "What elements are necessary, in a high-tech scientific and technical research work environment, for African-Americans to experience job satisfaction?"

Many studies have been conducted in the area of job satisfaction. Its necessary attributes or components have been studied, analyzed, validated, standardized, and normed, on predominantly white male populations. Few of these studies have focused on people of color, specifically African-Americans, and fewer still on those AfricantAmericans working in a high-tech, scientific and research environments. The researchers have defined what is necessary for the current dominant culture's population, but are their findings applicable and valid for our nation's other cultures and ethnic groups?
\end{abstract}




\section{VITA AUTORIS}

Name

Date of Birth

High School

Graduated:

Baccalaureate Degree:

College:

Graduated
Cheryl Delemos Krossa

February 10, 1954

All Saints Cathedral School

St. Thomas, U.S. Virgin Islands

1972

Bachelor of Arts Degree

Carthage College

Kenosha, Wisconsin

1976 


\section{ACKNOWLEDGMENT}

To my family, friends and colleagues whose love, encouragement and faithful support have been a source of strength throughout my Master's Program, we have shared more than an academic process we have forged a stronger bond between us in this achievement.

And, to my African-American colleagues, who participated in this study, you have given back to the community ten fold. I have appreciated having the chance to get to know each of you better, and by doing so learning more about all of us. 


\section{LIST OF TABLES}

Table

Page

3.1 Gender compositions of all Full-Time African-American Employees and African-American Scientific and Technical Professionals.

3.2 Frequencies and Percentages of Full-time African-American Employees by Job Groups/Titles and African-American Scientific and Technical Professionals (AASTP)

3.3 Frequencies and Percentages of Educational Attainment of all African-American Full-time Employees and African-American Scientific and Technical Professionals (AASTP).....

3.4 Frequencies and Percentages by Years in the Organization of all African-American Full-time Employees and African-American Scientific and Technical Professionals (AASTP)

4.1 Frequencies and Percentages by Job Classification of African-American Scientific and Technical Professionals (AASTP) and Study Participants (SP).....

4.2 Frequencies and Percentages of Educational Attainment of African-American Scientific and Technical Professionals (AASTP) and Study Participants (SP)

4.3 Frequencies and Percentages by Years in the Organization of African-American Scientific and Technical Professionals (AASTP) and Study Participants (SP).

4.4 Frequencies and Percentages by Years in their Field of African-American Scientific and Technical Professionals (AASTP) and Study Participants (SP) 
4.5 Interview Analysis - Themes and Frequencies

Question \# 7 - Why did you go into this field?

4.6 Interview Analysis - Themes and Frequencies

Question \# 8 - What have you enjoyed most about

working in this field?

4.7 Interview Analysis - Themes and Frequencies

Question \# 9 - What have you enjoyed least about

working in this field?

4.8 Interview Analysis - Themes and Frequencies

Question \# 10 - What things satisfy you about your job

here?

4.9 Interview Analysis - Themes and Frequencies

Question \# 11 - What things dissatisfy you about your job

here?

4.10 Interview Analysis - Themes and Frequencies

Question \# 12 - Do there seem to be different satisfiers from

other colleagues who are white?

4.11 Interview Analysis - Themes and Frequencies

Question \# 13 - How would you define success for

yourself?

4.12 Interview Analysis - Themes and Frequencies

Question \# 141 - Do you feel that you have been

successful? 


\section{LIST OF APPENDICES}

Appendix A

Appendix B

Appendix C

Appendix D

Appendix E
Beginning Interview Questions

Invitation To Participate As A Research Subject

Interest Indication Response Form

Consent To Be A Research Subject

Interview Analysis (IA) Form 


\section{Chapter 1}

\section{INTRODUCTION}

The purpose of this study was to begin to develop an answer to the question, "What elements are necessary, in the work environment, for African-Americans to experience job satisfaction?"

Many studies have been conducted in the area of job satisfaction. Its necessary attributes or components have been studied, analyzed, validated, standardized, and normed, on predominantly white male populations. Few of these studies have focused on people of color, and fewer still on those African-Americans working in a high-tech, scientific and technical research environment. The researchers have defined what is necessary for the current dominant culture's population. The question still remains, are their findings applicable and valid for our nation's other cultures and ethnic groups?

\section{Background of the Issue}

Throughout our nation's relatively brief history, African-Americans have contributed to our scientific and technical excellence. Men like Benjamin Banneker (1731-1806), an inventor, mathematician and Almanac-Maker not only built the first clock made in America in 1761, but went on later to earn an even greater reputation as a part of the six man team that laid out the blueprint for Washington, D.C. Agricultural Scientist, George Washington Carver (1864-1943); Physician and Blood Plasma Researcher, Dr. Charles Drew (1904-1950) and Physicist and NASA Astronaut, Dr. Ronald E. McNair (1950-1986) are but a few of the African-Americans who have made lasting contributions in the realm of science and technology.

The achievements of these individuals, as well as other African-Americans in science and technology, have been obscured not only by racial prejudice, but by the 
replacement of the individual contributor or inventor by government and corporate research and development teams. Individuals, regardless of their race, receive less and less recognition. The creators of the computer, television, heart pacers, and lasers have vanished into obscurity. As a result, it is difficult to know how many African-American scientists have received patents in recent years. However, African-American scientists and engineers have played a substantial role in the development of solid state devices, high powered and ultra fast lasers, hypersonic flight and elementary particle science. With increasing numbers of black students interested in science and technology and a national focus on the inclusion of African-American and other students of color in scientific and technical curriculums, future opportunities abound.

Cultural diversity in the workplace has become, and continues to be, of major concern to government and industry (Rubaii-Barrett \& Beck, 1993). No longer is the United States considered to be the "Melting Pot" it was during the years of significant European immigration, when a homogeneous culture was desirable. One of this nation's earliest immigrant groups, African-Americans, by virtue of their race, were never included in this process and continued to live outside the "Melting Pot," maintaining their own unique culture in their communities, and quite often in the work place. Modern day immigrants, the preponderance of whom are not Caucasian, as well as native AfricanAmericans have found a common bond in that they, too, want to maintain some of their cultural values in the workplace. This new perspective, at times referred to as the "Salad Bowl," has sparked concern in the American workplace.

Reports by the Hudson Institute (1987) and the U.S. Office of Personnel Management (1988) indicate that employers are worried about their ability to: motivate diverse groups of employees; effectively communicate with their employees; and comprehend the impact of differences in values and cultural norms on employee performance, commitment and job satisfaction. These concerns are supported by the fact 
that the work force will be even more heterogeneous in the future than it is now. According to the Statistical Abstract of the United States, 1992: The National Data Book (1992), in the past ten years, the population of the United States has continued to grow at a rapid rate with a $6 \%$ increase in the population of those individuals identified as Caucasian. At the same time, among those individuals of color, population growth was even greater African-American, 13.2\%; American Indian, 37.9\%; Asian or Pacific Islander, 107.8\%; Hispanic, 53\% and Other 45\%. With this continued growth trend, there will be over 16.5 million African-Americans employed in the civilian labor force by the year 2000 .

\section{Statement of the Issue/Problem}

From a global perspective, the United States no longer holds the economic position it once did. This is the result of the shift to a more international economy, one in which there is the increased availability of cheap labor and business incentives provided by other countries. The enticements presented to global manufacturers, including our own U.S. manufacturers, have made the North American manufacturing alternative cost prohibitive. Skyrocketing labor costs and governmental regulations at the federal, state and local levels have driven many manufacturing and "low tech" companies out of the United States in the past ten years. This corporate exodus has taken its toll. As a nation, we have experienced a shift in the national balance of trade and its impact on our cost of living. This exodus and its resulting shift has also resulted in changes in the types of jobs still available to U. S. employees to careers in "high tech," technical and scientific research and development jobs. No longer are we manufacturers; as a nation we have become designers and developers with more and more of our jobs being requiring higher and higher levels of education and skills. These types of jobs will be the future for U.S. employees. As the demographic figures have indicated, these jobs will also be the future for African-Americans. 
The new American "Salad Bowl" perspective has also fostered a new generation of scientific and technical researchers. They bring with them not only their education but the views of their cultural perspective on science and technology, as well as nontraditional views and experiences of their minority communities. These perspectives often are, in direct conflict with the teachings of the dominant culture's educational system. As a result, minority scholars have begun to explore various ethnic perspectives on science and technology. They are looking at how they compare with the prevailing perspectives of the dominant culture, and their impact on scholarship, professional practices and policies (Frankel, 1993).

Many institutions, including the one in which this study took place, have begun to focus on the development of their employees' awareness of the value of a culturally diverse work force. In the organization in which this study took place, this process of valuing cultural diversity is being done as a part of a greater multi-institutional initiative on cultural diversity. This initiative focuses on contributing to the welfare of the nation by using its multi-institutional scientific and technical talent to fuel a competitive economy. To achieve this mission, all participating institutions, of which this organization is a part, have focused on "creating an atmosphere that fully utilizes the talents and capabilities of a diverse work force"(U.S. Department of Energy, 1994, p.1).

This new diversity initiative comes at a time when federally funded scientific and technical research institutions such as this organization are experiencing significant funding cuts. This has resulted in large scale reorganizations of departments and programs. In a proactive attempt to better meet the needs of its employees, this organization initiated the development and administration of an organizational wide job satisfaction survey. In this environment, the question should not be "IF" the employees are satisfied, but what needs to be present for their job satisfaction? With the knowledge of what contributes to the employees' job satisfaction, the question of whether or not they 
are satisfied loses its importance because then steps can be taken to ensure an environment in which greater job satisfaction can be achieved. When asked if they are satisfied employees will quite often indicate that they are. All that is then achieved is a relative comparison of the level of satisfaction among the different groups within the population, not what constitutes job satisfaction for these groups or what must be present for a particular group to be satisfied.

\section{$\underline{\text { Normative Definitions }}$}

As a qualitative study the purpose of the research is to begin to identify and bring to light the variety of characteristics or elements that affect the existence and level of job satisfaction or dissatisfaction. It is these elements or characteristics that will emerge as a result of this study, and ultimately be the source of normative definitions for future research.

The role of the researcher in this study is to document, analyze and identify possible patterns, in essence becoming a "cultural broker" and "scribe" (Schwartzman, 1993, p.47). A cultural broker understands the differing cultures and interests within an organization and uses this knowledge to facilitate and encourage greater understanding of and resolution of conflicts between the differing groups. As a scribe the researcher's role changes to that of documenting the complex worlds within an organization.

\section{Research Objectives}

What does this select group of African-Americans, working in a scientific and technical research environment, find necessary for job satisfaction? The identification of these elements will be unique compared to most other studies. Their narratives will include experiences and provide a more functional perspective to the definition of job satisfaction. An analogy to this would be asking an individual who has lived in a subtropical climate his or her whole life to define snow. Though their definition of snow 
would probably be technically accurate, it would lack the depth and perspective of that provided, by someone who has experienced snow in all of its forms. The participants in this study, in a sense, all live in the North intimately experiencing snow in all of its manifestations. They glean their identities which are in part shaped by the positions they hold within this scientific and technical research environment. From this intimate knowledge and experience in this type of environment, they have developed personal definitions of what makes work satisfying for them and what they find rewarding. Conversely they also know what they would avoid and what is un-satisfying.

The material collected through the interviews was reviewed in an effort to synthesize from it what characteristics are necessary for job satisfaction, not only for the individual, but the collective group, by attempting the possible identification of patterns in their narratives. In other words, are these African-Americans motivated by standard identified needs for job satisfaction.

The interview questions were designed to be open ended in an attempt to encourage the informant to expand on his or her thoughts within a loose framework. The objective of the interview questions was only provide a framework for exploration and to encourage the sharing of personal experiences and stories.

\section{Importance of the Study}

In light of the cultural diversification of our work forces and the United States, and increasing involvement in a more global economy, jobs of the future will be in the technical and scientific research and development arenas. This study will begin to provide the foundation of what might be considered relevant factors necessary for job satisfaction for African-Americans, as well as the basis for further study amongst other ethnic and cultural groups such as Hispanics or American Indians. With the identification of what is necessary for job satisfaction, researchers will be better able to 
assess the levels to which it exists for African-Americans, versus conducting assessments with tools designed for a different cultural or ethnic population.

How can industry, academia, and society begin to address the needs of a diverse population, when little is known about non-Anglo cultures? It is necessary for us to begin to define a culture from its perspective in order to better understand it. Researchers tend to continue to compare other cultures or cultural artifacts to the "norm", whether it's an IQ score or job satisfaction. Anthropologists would call that "ethno-centric". It is necessary to begin to explore another culture's perspective from within that culture and try to address its needs as defined by that group. In addition, this research could provide an interesting starting point for a comparison of the impact of acculturation of a culture comparing these findings to those of other African-Americans in different professions, social and economic standings.

To the scientific and technical research organization in which the study takes place, hopefully the results of this study will provide managers with information that will enable them to begin to understand what is necessary to meet the job satisfaction needs of African-American employees. With this they could then begin to integrate into the organization's system means to enhance the level of job satisfaction of AfricanAmericans and to explore the needs of other cultural groups within the organization.

According to the literature, there are a strong relationships between job satisfaction and industrial, social and economic issues including worker and corporate productivity, worker behaviors, and quality of work life. Improvements in job satisfaction could yield important improvements in a variety of other areas all to the benefit of the organization and its employees.

\section{Limitations of the Study}

Though there is potential benefit from the findings of this research, there are several possible obstacles, not the least of which is the identification of the population. 
By traditional definitions, African-Americans have been defined as one distinct and unique racial and ethnic group. As we become more aware of our culturally diverse society, the definition of "African-American" becomes less and less clear. Increasingly, bi-racial and multi-racial individuals have chosen not to select one race over the others. Though having one parent who is African-American, they may not identify themselves as such.

There is also the issue of acculturation. Does the culture in which an individual grows up, and accepts as theirs, define their racial or ethnic identity? We are becoming increasingly more aware of the cultural divisions within the African-American population, such as foreign-born blacks from the Caribbean, Africa, Europe, and South America. Each of these regions contains a multitude of unique national and microcultures, unique and different to that which has traditionally been defined as AfricanAmerican, those who are North American continental-born.

There is also then the question of the current state of the work environment. As a national laboratory the research thrust has traditionally been in the area of weapons and defense research, as well as other national initiatives. As an organization, it operated in a relatively financially stable environment in which funding for defense research was secure and readily available. In recent years, significant geo-political changes, such as the fall of the Berlin Wall and the subsequent dissolution of the former Soviet Union, and a change in our own presidential administration, has meant the threat of a decrease in available funding for weapons and defense research. There has also been an increase in the need for the expansion and diversification of research, including joint ventures with industry, to insure sufficient funding to remain viable. This cultural shift and uncertainty, in a formerly stable environment, has resulted in a high level of anxiety in all employees and a possibly greater level of anxiety in African-American employees who frequently lack the seniority of their white peers. 
Beyond these issues there are the concerns of the development of trust, respect and openness on the interpersonal level. This study is based on a series of interviews with African-American employees, within a scientific and technical research organization, by another employee. For this study to provide meaningful and helpful information, it is important that, in a very brief time, a level of trust and respect is developed. This is necessary to obtain as much information from the study's informants as possible and at the same time address possible personal agendas on the part of the informants.

In in addition to these specific limitations, there are some more general limitaitons to this type of study. First, interviews as a method of gathering information are inherently limited,because they are not observations of real behavior, so therefore questionalble as the source of true operational definitions of the variable. Next, there is the issue that this is a sampling of a population. Any patterns which might be identified are suspect. They may not be the norms of thel larger population, but an anomaly. This could be the result of the sample size and or because it is all from a single organization. 


\section{Chapter 2}

\section{REVIEW OF RELATED LITERATURE}

\section{$\underline{\text { Purpose }}$}

As stated in the first chapter, many studies have been conducted in the area of job satisfaction. Its necessary attributes or components have been studied, analyzed, validated, standardized, and normed, on predominantly white male populations. Few of these studies have focused on people of color, in specific African-Americans, and fewer still on those African-Americans working in high-tech, scientific and research environments. This raises the question, are the criteria for the current dominant culture's population applicable and valid for our nation's other cultures and ethnic groups? Or is it necessary to begin to define what elements are necessary, in the work environment, for different cultural and ethnic subgroups; and in the case of this study, African-Americans specifically to experience job satisfaction.

\section{Why Do We Work? (Motivation)}

From the Greeks and Romans, for whom work was a despoiler of the spirit, to the Calvinists, who found in work the will of God, to the Victorians and Bolsheviks, who linked work to respectability, conceptions of work have twisted and turned with the passage of time (Tausky, 1992). The constant throughout history is the reality of work and the opposing views as to why we work. Work, whether voluntary or imposed, natural or "socially contrived", attractive or repellent, is an integral part of most of our lives.

From a pessimistic perspective, work is avoided unless there is an external force encouraging its existence, such as economic or social demands. Theorists such as Rensi, Skinner, Collins, Bleau, Homans and Freud support the perspective, that: " ...only will- 
power can drive us to work. Since work itself is not a pleasure, man conquers his native dislike of work only because necessity makes him work to possess the things he desires..."(Tausky, 1992, p.6). Humanity has often demonstrated this perspective in its behavior and attitude towards work by pointing to what has been obtained through work and what it has "cost" (Tausky, 1992, p.6). It is Freud's perspective which can be seen as starkly negative in its view of work:

As a path to happiness, work is not highly prized by men. They do not strive after it as they do after other possibilities of satisfaction. The great majority of people only work under the stress of necessity, and this natural human aversion to work raises most difficult social problems.(Freud, 1961, p.27)

Freud and the other "pessimists" relied on social necessity or external reward to act as the motivation to prod humanity into this unnatural condition. These theorists placed social control mechanisms at the center of work activity. We work because society or our culture dictates that we do so.

Juxtaposed to the pessimistic view lies the "optimistic" perspective. Theorists such as McGregor, Herzberg, Maslow, and Argyris have shared the premise that work need not be a burden, because the desire to work is inherent. While there is agreement amongst these theorists on humanity's inclination towards work, Argyris disagreed on its origin, contending that the desire to work is learned by the members of our culture.

One of the most notable of the "optimists" is Karl Marx, who captured the essence of work motivation in his analysis of alienation. Marx's alienated worker didn't own the products of his labor, he sold his labor to another who dictated the rules, division of labor and pace of work. Marx theorized that it was this lack of control which resulted in the alienated laborer. With control and equality, the elimination of the capitalist system, work is part of the "nature" of the worker. According to Marx, in a non-alienated workforce work would be fulfilling; it would satisfy the need for productive activity; it 
would spontaneously stimulate physical and mental energy; it would respond to humans' nature (Tausky, 1992).

Peter Senge (1990) captured the depth to which our job is our identity. We have been trained to be loyal to our jobs, so much so that quite often they are our identity. Senge sites the example of the closing of a large American steel company that offered to retrain displaced workers for new jobs. When after the retraining the workers quickly began to drift into unemployment and odd jobs, psychologists wanted to know why. What they found was that the steelworkers were suffering from acute identity crises (Senge, 1990, p. 18). The employees in the steel company, as with many of us, took their identity from the tasks they performed every day, and not from the purpose of the greater enterprise. We define ourselves within the greater system, over which we have little control within the boundaries and the definition of our roles, over which we do exercise some control. Without this we lose a critical portion of our identity. Our society reinforces this view even in its social settings. When we are introduced to someone new as part of our ritual greetings, almost immediately after sharing your name with the person, the next identifying factor is what you or they "do." In situations where either of the parties can not define themselves by their work, such as they are unemployed, there is great pause as all parties attempt to define this person in light of this cultural "nonidentity".

To begin to explore ethnic and racial differences at work, it is necessary to view job satisfaction as a product of social, psychological, and cultural factors that affect the attitudes and beliefs of workers (Rubaii-Barrett \& Beck, 1993). It is then safe to propose that if job satisfaction is the product of all these factors, members of particular cultural or ethnic groups are predisposed to respond differently to experiences in organizations because of their unique attitudes and beliefs. These differences among some subgroups of employees may persist even after long periods of socialization. Early studies 
conducted primarily in private industry and which focused on African-American and Anglo employees, found job satisfaction among the African-American population to be lower or no different from that of Anglos (Rubaii-Barrett \& Beck, 1993, p. 504). In more recent studies conducted in the public sector, however, workers from minority groups were more satisfied than Anglos (Rubaii-Barrett \& Beck, 1993, p. 514). It was theorized that, in part, this can be possibly attributed to the larger number of African-Americans and other minorities in government, and the efforts of governmental agencies to play a role in the inclusion and assimilation of various cultures and ethnic groups. The visibility of the efforts to include women and people of color as well as the visible status and security of those individuals in public service; and the relatively higher wages paid this group than in the private sector, resulting in less pay inequities in comparison to their Anglo co-workers, have made government jobs desirable to members of these groups (Mladenka, 1989; Stein, 1986; Dye \& Renick, 1981).

\section{Job Satisfaction}

What do the burgeoning changes to our national cultural perspective, increased demographic representation of minorities and the national shift to technological and scientific research mean for African-Americans and their job satisfaction?

It is a commonplace assertion that worker dissatisfaction accounts, at least in part, for a host of contemporary industrial, economic, and societal problems, including declining worker and firm productivity; pathological worker behaviors such as sabotage, employee theft and absenteeism; low levels of worker commitment; increased levels of worker substance abuse; and reduced overall quality of life. If this is the case, it is critical to ensure job satisfaction.

First, job satisfaction must be defined. It is, in essence, "the result of the worker's appraisal of the extent to which the work environment fulfills the individual's needs," "a pleasurable affective condition resulting from one's appraisal of the way the experienced 
job situation meets one's needs, values and expectations" (Dawis \& Lofquist, 1984, p.72). As an area of research and study, the focus on job satisfaction is not a new and passing fad. Studies have reported that job dissatisfaction in related to the risk for heart disease, hypertension and high cholesterol levels, narcotics use, depression, low selfesteem, work-related illness and injury, overall dissatisfaction with life, and high turnover and absenteeism (Perry, 1992). With this information, worker job satisfaction ceases to solely be a social or ethical issue, but an economic imperative.

Standardized job satisfaction scales date back into the 1930s. Since the '60s, two standardized job satisfaction questionnaires, the Job Descriptive Index (JDI) (Smith, Kendall, and Hulin, 1969) and the Minnesota Satisfaction Questionnaire (MSQ) (Weiss, Dawis, England and Loftquist, 1967), have been in the forefront of satisfaction measurement. Programmatic research on these measures has succeeded in documenting their psychometric properties (Rentisch \& Steel 1992). The JDI and the MSQ are suitable for a wide variety if research applications. Their many advantages include subscale scores corresponding to various subdimentions or facets of overall job satisfaction(e.g., extrinsic satisfaction, satisfaction with coworkers) and an overall job satisfaction score (Rentisch \& Steel, 1992).

JDI is one of the most widely used measures in organizational sciences today to measure job satisfaction. Its subscales measure levels of satisfaction with each of the following: the work itself, supervision, coworkers, pay and promotions. It is commonly accepted that the JDI behaves consistently over a wide variety of situations and has reasonably high reliability (Buckley, Carraher, \& Cote, 1992).

What both of these measures fail to consider is the impact of the identity and culture that the individual brings to the work environment and that how individuals feel about their lives will effect how they process job information (Judge \& Watanabe, 1993). In addition, it has been found that there is a strong directional relationship between job 
and life satisfaction that is equivalent in magnitude (Judge \& Watanabe, 1993, p.947). The effect of life satisfaction on job satisfaction is significantly stronger than the effect of job satisfaction on life satisfaction (both in the short interval and long term) Over time, longitudinal studies have shown that both relationships, (the effect of life satisfaction on job satisfaction and the effect of job satisfaction on life satisfaction), become weaker. Theoretically, the cross-sectional results measure nearly instantaneous effect of job satisfaction and life satisfaction on one another, whereas the longitudinal results measure effects over a considerable time interval, 5 yrs. (Judge \& Watanabe, 1993).

Of the thousands of studies that have been conducted on job satisfaction relating it to industrial, social and economic issues including worker and corporate productivity, worker behaviors, and quality of life, traditionally, sociological explorations of job satisfaction have focused on two key models; the structural model and the dispositional model. The structural model can also be called the situational, positions or "good jobs" model. This model focuses on the characteristics of the job itself, (e.g., the level of intrinsic and extrinsic rewards, autonomy, authority, skill utilization, prestige, pay and security, the corporation, (e.g., size, hierarchy, closeness of supervision, management style), and the industry (e.g., production technology, and quality of working conditions) (Tuch \& Martin, 1991, p.104).

The dispositional model presents the perspective that work means different things to different people. The interaction between objective characteristics and the worker's disposition, creates job satisfaction (Tuch \& Martin, 1991). This suggests that employees' satisfaction will vary with respect to subjective factors such as values, expectations and needs and that these factors are impacted by age, family and wage earning responsibilities, education, community characteristics, and race (Tuch \& Martin, 1991). In their 1991 study "Race in the workplace: black/white differences in the source of job satisfaction" Tuch and Martin found support for the structural model in that their 
data yielded more uniformity than variation across racial groups, which was consistent with earlier research of Lincoln and Kallenberg (1985). In other words, the process that produces worker satisfaction does not systemicly vary by race.

What still remains unclear is the cultural perception of the measured variables. Are extrinsic rewards the same across cultures? Are cultural values the same around pay, or prestige? If they are, how can entire cultures yield consistently lower levels of both job and life satisfaction? Diener (1984) concluded that minorities generally have been found to have lower life satisfaction than whites. This, he theorized, was perhaps because of their urban city and lower socioeconomic status. In fact it is often the elements of location and economics that help define a cultural group.

\section{High Tech Job Satisfaction}

Lack of empirical data concerning job satisfaction in high tech industry is a glaring omission in view of high tech's presumed economic significance and its purported leadership for new kinds of organizations and work behavior (Gamst \& Otten, 1992). According to Gamst and Otten (1992) in their study: "Job satisfaction in high technology and traditional industry: Is there a difference?" found that there is a positive relationship between job technological change and increased job satisfaction for both men and women workers. Although the degrees of satisfaction were virtually the same for high technology and traditional work, relatively large differences divided social classes within the workplace (Gamst \& Otten, 1992, p. 413). Job satisfaction in this study seemed to be a function of social class and its attendant ownership, control relations, and differential rewards. The high tech work force did not consistently enjoy higher levels of job satisfaction relative to their non technical counterparts. Instead, comparable levels of composite job satisfaction were found for both industrial sectors. The lack of job satisfaction differences between the two sectors is not the technological differences, but the differences of opportunity, which may reflect class differences. 
The National Science Foundation predicts a shortage of 400,000 scientists in the USA by the year 2006 (Holden, 1989). Knowledge of work-related attitudes of scientists should help provide recommendations for attracting more people to the field in the future as well as provide a basis for immediate improvements in the management of currently employed scientists in academia, industry, and government settings (Trankina, 1991).

Though work related attitudes of workers have been analyzed extensively, and the literature shows that among all occupations, professionals are the most satisfied, little is known about specific groups of professionals, and this includes scientific professionals. In a recent study by Trankina (1991), it was found that: $50 \%$ of scientists from a sample representative of the entire U.S. population report dissatisfaction in their work, and that the variables of importance to scientists were (most important to least): (1) Important meaningful work, (2) income, (3) chances for advancement, (4) short hours, (5) security.

\section{$\underline{\text { African-American Job Satisfaction }}$}

Little prior research explicitly addresses racial differences in the sources of job satisfaction. Surprisingly little is understood about African-American's job satisfaction beyond the substantial evidence that they report lower absolute levels. Why are black workers less satisfied than white workers? Does race condition the relationship between job satisfaction and its correlates such that different levels of satisfaction between blacks and whites reflect a racial difference in the process that produces satisfaction? Is this process universal, invariant across racial groups, and blacks' lower job satisfaction explained by their relative disadvantage on those factors that promote satisfaction? Maybe what happens is that though the process is found to be equal, the resulting lower absolute levels is due to the fact that what is measured may not be valid for this group (Tuch \& Martin, 1991).

For more than two decades, the U.S. news industry has been under pressure to employ and promote African-Americans, Hispanics, and other ethnic minorities. In their 
study of African-American job satisfaction in the industry, Bramlett-Solomon applied Herzberg's motivation-hygiene theory. Herzberg's two-factor concept contends that intrinsic job factors contribute to job satisfaction (such as achievement, responsibility, chance for advancement) while extrinsic factors (such as company policy, supervision, salary and working conditions) contribute to job dissatisfaction. The findings in this study are evidence that certain job factors do motivate black journalists on the job. The strongest predictor of job satisfaction was inclusion and power in reference to hiring and firing. The percentage of those not satisfied however is about twice the rate of white journalists, and there is seemed to be a strong presumption of prejudice, whether "real" or not (Bramlett-Solomon, 1992).

In their work "Race in the workplace: black/white differences in the source of job satisfaction" Tuch \& Martin (1991) found little evidence that the process that produces worker satisfaction differs systematically by race. Blacks' lower work place satisfaction stems not from differences in the process that determines satisfaction, but from their relative disadvantage in several of the individual-, firm-, and industrial-level characteristics which are measured, that promote satisfaction. The sources of job satisfaction typically identified for white workers will affect blacks differently; that is, the process is moderated by race, and race specific models are necessary to characterize it. A case in point is the distinction between intrinsic and extrinsic job rewards. An inverse relationship between social class position and the valuation of extrinsic rewards is commonly reported, and that this class effect translates to race effect, blacks value extrinsic more than intrinsic job rewards.

These "disadvantages", in part, can stem from ethnic and cultural values that can conflict with those of the dominant "Anglo" culture. For example, in our health care system, most medical personnel place a high value on full disclosure to patients. However, immigrants from Ethiopia regard disclosing a serious illness to a patient as 
conflicting with the patient's hope for healing. Doctors are expected to cooperate with the family in protecting the patient from bad news (Frankel, 1993, p. B2).

The project "Viewing Science and Technology Through a Multicultural Prism", outlines how mental therapy aimed at blacks, has resulted in poor outcomes because therapists, most of whom are white, have not been sensitive to the historical realities of racism and discrimination that effects the everyday lives of blacks (Frankel, 1993). Differences in cultures and ethnic responses to medical and social situations make it inappropriate, even dangerous, to generalize findings based on research that has largely excluded members of minority groups. The recent policy decision by Congress and the National Institutes of Health mandating the inclusion of ethnic minorities in clinical trials constitutes acknowledgment of past neglect of scientific researchers. Women have also suffered the same neglect (Frankel, 1993).

All scientific inquiry requires a perspective, for research is not only investigation but also interpretation. Language is a cultural product, cultures vary, and so does language and the way language is used to organize and define the meaning of experience (Leigh, 1976). Language is a window to the reality defined and experienced by others, to understand and interpret the experiences and sense of reality of others. One must know how they use language. In essence, language is a form of behavior, and as such, scientists' perspectives of their language, and that of their research subjects, condition what they see as important for the advancement of science, as well as research (Frankel, 1993). 


\section{Chapter 3}

\section{METHODOLOGY}

\section{$\underline{\text { Informants }}$}

The population for this investigation was a subset of all the self-identified African-American, full time career employees at a San Francisco Bay Area scientific and technical research institution. The population of African-Americans was 334, 4.7\% of the organization's total population. For the purpose of this research project only those employees who are considered professionals and hold scientific or technical job classifications were included: Biochemist, Biomedical Scientist, Biologist, Environmental Scientist, Biophysicist, Chemist, Engineer, Mathematician, Medical Doctor, Metallurgist, Physicist, Physiologist and Computer Scientist/Math Programmer. The total number of African-Americans holding these types of jobs is 47 .

- Gender: Table 3.1 The gender composition of full-time African-American employees, is provided by the frequency distribution of this population, as well as the relative percentages of each. This is as it compares to the informant group of this study. 
Table 3.1

Gender compositions of all Full-Time African-American Employees and African$\underline{\text { American Scientific and Technical Professionals }}$

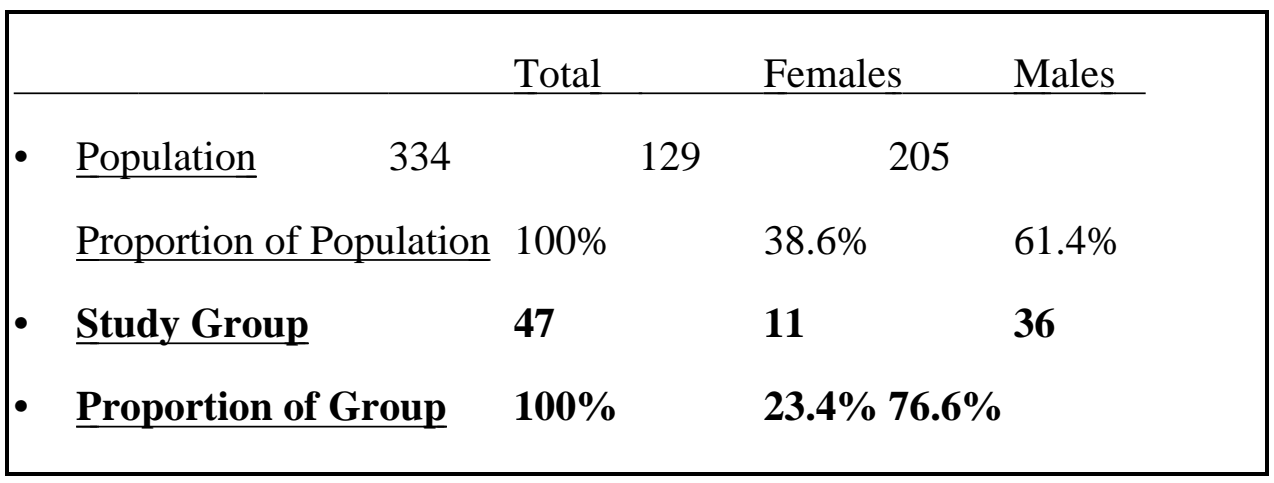

- EEO-1 Job Groups: A "Job Group" is a grouping of jobs cutting across organizational lines. Jobs that are grouped together are those with "similar (job) content, wage rates and (promotional) opportunities," (U.S. Department of Labor, 1993, p.20) irrespective of department or line progression. The job group is the basic unit for Affirmative Action and Equal Employment Opportunity analysis and monitoring.

The foundation on which job groups are built are "EEO-1" Job Categories, of which there are nine, (A) Officials and Managers; (B) Professionals; (C) Technicians; (D) Sales; (E) Office and Clerical; (F) Craft Workers, Skilled; (G) Operatives, semi-skilled; (H) Laborers, unskilled; and (I) Service Workers. The organization in which this study was conducted is unique in its function, and as a result it was necessary to modify these groupings to better reflect its population. As a result there are eight EEO-1 groups or categories: (A) Managers and Supervisors; (B) Professionals; (C) Technicians; (D) Office and Clerical; (E) Crafts People; (F) Operators; (G) Gardeners; and (H) Service People 
(Lawrence Livermore National Laboratory, 1994, p. 141). This study will limit its focus on the scientific and technical professionals in the "B" or Professionals job group.

The organization in which this study was conducted has aggregated its job titles into 48 groups of jobs that have similar responsibilities and skills, similar wage and salary structures, and similar feeder jobs. These groups are used to determine employee distribution. Job titles are combined into job groups with a minimum of 50 employees wherever possible. Job titles may appear in more than one job group because employees who are assigned management and supervisory responsibilities do not, with some exceptions, change job titles. The 48 job groups, and the numerical distribution of the African-American employees and the informants of the study group in each job group, is shown in Table 3.2. The informants in this study, because of their professional standing were primarily from the "A" and "B" job groups. As a result, they also represented a highly educated portion of the overall population.

- Education: The distribution of African-American Employees by their highest academic degree, and percentage of the population of all African-Americans in the organization, as well as this information as it applies to the informants in the group studied is shown in Table 3.3 
Table 3.2

Frequencies and Percentages of Full-time African-American Employees by Job Groups/Titles and African-American Scientific and Technical Professionals $\underline{(\mathrm{AASTP})}$

\begin{tabular}{|c|c|c|}
\hline Job Groups / Titles & Pop / AASTP & $\%$ Pop $/ \%$ AASTP. \\
\hline $\begin{array}{c}\text { A - Managers and Supervisors } \\
\text { Management - Scientific } \\
\text { Management - Administrative } \\
\text { Supervisor - Technical } \\
\text { Supervisor - Clerical } \\
\text { Supervisor - Nonclerical } \\
\text { Supervisor - Blue Collar }\end{array}$ & $46 / 7$ & $13.77 / 14.9$ \\
\hline $\begin{array}{l}\text { B - Professionals } \\
\text { Administrator } \\
\text { Physicist } \\
\text { Chemist/Metallurgist } \\
\text { Life Scientist } \\
\text { Computer Scientist } \\
\text { Engineer - Mechanical } \\
\text { Engineer - Electronics } \\
\text { Engineer - Miscellaneous } \\
\text { Tech. Info. Editor/Specialist } \\
\text { Environmental Scientist }\end{array}$ & $82 / 40$ & 24.55 / 85.1 \\
\hline $\mathrm{C}-$ Technicians & 77 & 23.05 \\
\hline D - Office and Clerical & 54 & 16.16 \\
\hline E - Crafts People & 19 & 5.68 \\
\hline F - Operators & 19 & 5.68 \\
\hline $\mathrm{G}$ - Gardeners & 0 & 0 \\
\hline H - Service People & 37 & 11.07 \\
\hline
\end{tabular}

Note. Figures in bold face type are frequencies of African-Americans and percentages of them in specific job groups who constitute the population of this study 
Table 3.3

Frequencies and Percentages of Educational Attainment of all African-American

$\underline{\text { Full-time Employees and African-American Scientific and Technical }}$

Professionals (AASTP)

\begin{tabular}{|lll|}
\hline Education & Pop. $(\%)$ & AASTP (\%) \\
\hline No-Degree & $25(7 \%)$ & 0 \\
AA/AS & $52(16 \%)$ & 0 \\
BA/BS & $61(18 \%)$ & $21(45 \%)$ \\
MA/MS/MBA & $31(9 \%)$ & $16(34 \%)$ \\
PhD/EdD & $12(4 \%)$ & $10(21 \%)$ \\
Undetermined & $153(46 \%)$ & 0 \\
\hline Totals & $334(100 \%)$ & $47(100 \%)$ \\
\hline
\end{tabular}

- Years in the Organization: The distribution of all full-time African-American Employees and the members of the group studied and their years of service in the organization, and percentage of population and group can be inspected in Table 3.4.

Table 3.4

$\underline{\text { Frequencies and Percentages by Years in the Organization of all African-American }}$ $\underline{\text { Full-time Employees and African-American Scientific and Technical Professionals }}$ (AASTP)

\begin{tabular}{|lll|}
\hline Years of Service & Pop $(\%)$ & AASTP $(\%)$ \\
\hline$<5$ & $114(14 \%)$ & $16(34 \%)$ \\
$6-10$ & $96(10 \%)$ & $13(28 \%)$ \\
$11-15$ & $44(5 \%)$ & $8(17 \%)$ \\
$16-20$ & $47(6 \%)$ & $8(17 \%)$ \\
$21-25$ & $20(2 \%)$ & $2(4 \%)$ \\
$26>$ & $13(1 \%)$ & $0(0 \%)$ \\
\hline Totals & $129(100 \%)$ & $47(100 \%)$ \\
\hline
\end{tabular}




\section{$\underline{\text { Research Design }}$}

In order to have a greater understanding as to what is necessary for job satisfaction for African-Americans in a technical and scientific research environment, a clear understanding must be developed as to what they feel is important, rewarding, fulfilling and necessary to achieve job satisfaction. In a sense, this study will explore the African-American perspective, beginning to identify what is unique to this group and the possible impact this might have on their interactions in the closed environment of this organization, and in their professional field, both of which are dominated by the Anglo mainstream culture. It is hoped that with the findings of this study a greater understanding will emerge of the culturally unique identification of job satisfaction for this group.

This study was composed of a series of informal one-on-one interviews, with a minimum amount of structure. A series of open-ended questions were developed with the intention that the conversations would become the catalyst for other questions, expanding on the informants' shared experiences and their relevance to job satisfaction (see Appendix A)

Interviewing is one of the most common and potentially powerful ways sociologists have to understand fellow human beings. The open-ended ethnographic interview technique was used in this study in an attempt to understand the complex behavior of the members of this group without posing any categorization that might be limiting. In the design of the project, it was important that the interviewer, as a student of human behavior seeking a greater understanding of the subject area, focus on jointly exploring with the informants their understanding and experiences of job satisfaction. Every effort was made to foster an environment of trust and mutual respect, with the aim of establishing a rapport with each of the informants. Therefore, it was important not to be seen as an instrument or agent of the organization. 
Gender as well as race played an important part in this research project. Gender differences between the researcher and the informant may, at times, have had an effect on the comfort level and candid responses of the informant. The similarity of race between the researcher and the informants may have had an impact on the research. Given the subject matter of the research, however, this impact was hopefully positive and facilitative. It was important that attention be focused on the needs of the research participants and that the researcher remained a neutral observer so that observations would not be filtered or interpreted by the researcher's own experiences.

It is important to maintain a commitment to integrity and preserving the viewpoint of the informants as expressed in their own language (Fontana \& Frey, 1994). It is this use of language and specific terms that is important for creating a situation of shared meanings (Fontana \& Frey, 1994), so that both the interviewer and informant understand the context of the interview.

\section{Procedures and Treatment of Data}

From data in the institution's personnel data base, all African-American employees who are categorized as Scientific or Technical Professionals (47 individuals) were sent letters that identified the researcher, and explained the purpose of this study, and invited the employees to participate in this research project (Appendix B). This initial letter included a self-addressed Interest Indication Response form (Appendix C), which was to be returned expressing the potential participant's interest, or lack there of, in participating in the study. Of these initial 18 respondents who indicated their interest in participating, a representative group of 10 individuals were initially selected for participation. The balance was later contacted by telephone to discuss and validate some of the patterns identified from the initial group of informants. The individuals who comprised the initial sample group of informants for this study were selected in order to create a group that reflected the organization's African-American population. These 
individuals in the initial sample group, as well as the others, were then contacted by telephone and sent a "Consent to be a Research Subject" form that they were to complete and return.

During the initial telephone contact, an appointment was scheduled to meet with the informant at a time and location that facilitated the interview process and ensured enhanced confidentiality and convenience. The interview was composed of a series of questions (Appendix A.) and took about an hour. These initial interviews were subsequently followed-up with phone conversations clarifying and validating developing patterns.

In order to ensure confidentiality, each informant was identified by a unique number that was held separate from all other identification data. This reduced the risk of inadvertent identification that might have resulted in the loss of confidentiality. In as much as all participants were volunteers, and the interviews were scheduled at a time and location for their convenience, there should have been minimal if no psychological stress related to the interview process.

During the interviews with the research informants, notes were taken and the conversations were tape recorded. The notes as well as the tape were identified by the pre-assigned identification code. After each interview, the resulting tape was transcribed and the transcripts of each subject as well as the notes from the interviews were reviewed.

The review of the transcripts consisted of identifying all references and content that related to job satisfaction. The first step is to develop a "classification of behaviors" (Babbie, 1992, p. 302), an organized list of the variety of concepts and issues. Each relevant concept is then identified by a theme. These coded findings were then consolidated with the findings from the other interviews. This process is intended to identify any patterns, or "norms of behavior" (Babbie, 1992, p. 301) which might appear among the members of the study group. It is this "discovery of universals" (Babbie, 
1992, p. 301) which is the purpose of this study. In addition, it is also critical to identify any differences from these norms (deviant cases) and note them. The informants are then called to discuss and clarify these emergent concepts. Once this is completed, these concepts can be grouped in order to identify if there are any norms of behavior. It is these findings and any resulting norms that will help begin to identify some of the elements of value to this population of African-Americans in this type of environment, and provide an insight as to what might be necessary for job satisfaction in this population at-large.

These norms are then tested by further interviews. Those individuals not originally interviewed as a part of the study, but who had indicated a willingness to participate, were telephoned and interviewed, over the phone, to further test initial observations.

The findings of this type of qualitative study will also need to be reviewed for the validity, reliability and generalizability of its results. Qualitative research of this type can and does yield valid measures of human behavior. The depth and comprehensive nature of this form of research is unavailable through the use of surveys or experiments. Instead of quantifying concepts, it is through qualitative research conducted in field studies that concepts, and operational definitions for future measurement are developed.

Unfortunately what this type of research gains in its validity it loses in its reliability. Though field research can provide a depth of study, it is based on personal observation and judgment. Conclusions and judgments can vary as the result of the changing perspectives of different researchers. It is important in this sort of study that the evaluations are comparative in nature, assessing one informant's attitudes against those of another, being sure to note both similarities and differences.

Finally, despite the thorough and in-depth knowledge gained through this type of research, generalizability of its results also poses a problem. First, as noted earlier, 
because of its dependence on personal observation, replication of the study could yield different results with a different researcher. Second, a qualitative study provides a great depth of information on a limited sampling, while losing the benefits of broader samplings of standardized measurements. Lastly, there is the great potential for sampling bias. There is no way to determine if the informants are truly typical, or if they are the exceptions to the broader pattern. Scientific talent and ability as possessed by these informants are rare enough encased in any color skin; they may not follow the "rules" for others less blessed.

\section{$\underline{\text { Operational Definitions }}$}

African-Americans, for the purpose of this study, are individuals who identify themselves as having cultural or ethnic origins in any of the Black racial groups of Africa. As a cultural and ethnic group, African-Americans make up approximately 12 percent of the American population and two percent of all employed scientists and engineers. As experts in one or more of the sciences (Webster, 1984, p.1045) such as physics, biology, chemistry, geology, etc., these scientists and engineers, who are trained or professionally engaged in a branch of engineering, i.e., chemical, civil, electrical, mechanical, etc. (Webster, 1984, p.433), are representative of the more educated segments of this as well as other cultures.

African-Americans earn four percent of the baccalaureates and one percent of the doctorates in science and engineering. In 1986, only 89 blacks who are U.S. citizens earned a Ph.D. in science, while there were 14 who earned that degree in engineering (U.S. Department of Energy, 1994). African-Americans started entering the fields of science and engineering in increasing numbers in the 1970s, as the result of the launching of minority engineering programs at several majority institutions (where the student population is predominantly Caucasian). From 1973 to 1985 the enrollment of AfricanAmerican undergraduate engineering students grew from 5,508 to almost 18,000. In 
more recent years there has been a notable decline, with last year's figures at 16,803 (U.S. Department of Energy, 1994). Despite this recent decline, African-Americans are an increasing part of the technical and scientific work environment- an environment whose rewards, recognition and systems have been designed to meet the job satisfaction needs of its historically white male environment.

It is the intent of this study to begin to identify similarities and differences and the concepts pertaining to what is necessary in a work environment for this population to experience job satisfaction. It is then from these findings that an operational definition of "job satisfaction" will emerge, as well as a definition of what it means to be an AfricanAmerican in this setting. 


\section{Chapter 4}

\section{FINDINGS}

The purpose of this study was to begin to develop an answer to the question, "What elements are necessary, in the work environment, for African-Americans to experience job satisfaction?"

Many studies have been conducted in the area of job satisfaction. Its necessary attributes or components have been studied, analyzed, validated, standardized, and normed, on predominantly white male populations. Few of these studies have focused on people of color, and fewer still on those African-Americans working in a scientific and technical research and development environment. The researchers have defined what is necessary for the current dominant culture's population. The question still remains as to whether their findings are applicable and valid for our nation's other cultures and ethnic groups.

In this chapter, results of this study will be presented. The first section is a general overview of the process and the results. This section is then followed by a breakdown of the findings, question by question, indicating possible relational factors where applicable. The question by question analysis focuses on actual quotations from the study participants and how these were interpreted.

\section{Overview}

The interviews that comprised this study took place over a three month period at a variety of locations and at different times of the day. This was done to accommodate the participants, hopefully providing them with an interview environment, in which they felt comfortable enough to be candid in their responses and encouraged to expand on their 
ideas, providing additional insight into their experiences. Of the initial 18 respondents who indicated their willingness to participate in this study, 10 were interviewed. This is approximately $30 \%$ of the total African-American population, $25 \%$ of the AfricanAmerican professional population, and $43 \%$ of the African-American managers and supervisors. Considerable efforts were made to ensure a group of study participants that was representative of the larger African-American scientific and technical population in the areas of job classification, education, years in the organization and years in their chosen field.

- Job Classification: The distribution of African-American Scientific and Technical Professionals who agreed to participate in this study, their Job Classifications and the distribution of study participants with the percentage distribution of their populations are shown in Table 4.1.

Table 4.1

Frequencies and Percentages by Job Classification of African-American Scientific and Technical Professionals (AASTP) and Study Participants (SP)

\begin{tabular}{|lll|}
\hline Job Classification & AASTP & SP \\
\hline BioMedical Scientist & $1(6 \%)$ & $1(10 \%)$ \\
Chemist & $3(16 \%)$ & $2(20 \%)$ \\
Engineer & $9(50 \%)$ & $4(40 \%)$ \\
Physicist & $1(6 \%)$ & $1(10 \%)$ \\
Computer Scientist & $4(22 \%)$ & $2(20 \%)$ \\
\hline Totals & $18(100 \%)$ & $10(100 \%)$ \\
\hline
\end{tabular}

- Education: The distribution of African-American Scientific and Technical Professionals by their highest academic degree, and percentage of the population of all 
African-Americans in the organization, as well as the distribution of participants and their percentage of the African-American Scientific and Technical Professionals is shown in Table 4.2.

Table 4.2

Frequencies and Percentages of Educational Attainment of all African-American $\underline{\text { Scientific and Technical Professionals (AASTP) and Study Participants (SP) }}$

\begin{tabular}{|llll|}
\hline Education & AASTP.(\%) & SP (\%) \\
\hline No-Degree & 0 & 0 & \\
AA/AS & 0 & 0 & \\
BA/BS & $21(45 \%)$ & 2 & $(20 \%)$ \\
MA/MS/MBA & $16(34 \%)$ & 5 & $(50 \%)$ \\
PhD/EdD & $10(21 \%)$ & 3 & $(30 \%)$ \\
Undetermined & 0 & 0 & \\
Totals & $47(100 \%)$ & $10(100 \%)$ \\
\hline
\end{tabular}

- Years in the Organization: The distribution of African-American Scientific and Technical Professionals and their years of service in the organization, and percentage of the population of all African-Americans in the organization, as well as the distribution of participants and their percentage of the African-American Scientific and Technical Professionals is shown in Table 4.3 
Table 4.3

Frequencies and Percentages by Years in the Organization of African-American $\underline{\text { Scientific and Technical Professionals (AASTP) and Study Participants (SP) }}$

\begin{tabular}{|lll|}
\hline Years of Service & AASTP $(\%)$ & SP $(\%)$ \\
\hline$<5$ & $16(34 \%)$ & $1(10 \%)$ \\
$6-10$ & $13(28 \%)$ & $6(60 \%)$ \\
$11-15$ & $8(17 \%)$ & $1(10 \%)$ \\
$16-20$ & $8(17 \%)$ & $2(20 \%)$ \\
$21-25$ & $2(4 \%)$ & $0(0 \%)$ \\
$26>$ & $0(0 \%)$ & $0(0 \%)$ \\
\hline Totals & $47(100 \%)$ & $10(100 \%)$ \\
\hline
\end{tabular}

- Years in the Field: The distribution of African-American Scientific and Technical Professionals, who agreed to participate in this study, their years in their field and the distribution of study participants with the percentage distribution of their populations is shown in Table 4.4

Table 4.4

Frequencies and Percentages by Years in their Field of African-American $\underline{\text { Scientific and Technical Professionals (AASTP) and Study Participants (SP) }}$

\begin{tabular}{|lll|}
\hline Years in Field & AASTP & SP \\
\hline$<5$ & $3(16 \%)$ & $1(10 \%)$ \\
$6-10$ & $5(28 \%)$ & $4(40 \%)$ \\
$11-15$ & $4(22 \%)$ & $1(10 \%)$ \\
$16-20$ & $4(22 \%)$ & $4(40 \%)$ \\
$21-25$ & $1(6 \%)$ & 0 \\
$26>$ & $1(6 \%)$ & 0 \\
\hline Totals & $18(100 \%)$ & $10(100 \%)$ \\
\hline
\end{tabular}


The process as a whole flowed relatively smoothly. I was struck by how candid the participants were during the interview and their interest in the results of the study. It was interesting to note that despite their candor, there was a seeming increase in the comfort level at the end of each interview once the tape was turned off. These un-taped conversations provided additional insight into the participant's feelings on some of the issues as well as additional anecdotes that seemed to support what's been recorded earlier. Despite all efforts to tape the entire conversation, it continued after taping was concluded, sometimes even extending to the hall way or rest room. Hand written notes were taken whenever possible during these times and these only added to the taped material. The level of interest in the study was such that contacts were frequently offered for further research at other companies.

\section{Question by Question Analysis}

- "Why did you go into this field?

To this, the first question in the survey, there were 11 themes which surfaced throughout the conversations. The most frequently identified response was the existence of a role model or mentor. This was followed by exposure to the field. The others fell far below in frequency, but they included, in descending frequency order: "it sounded interesting", "intellectual challenge", "job or career security", "concrete results", "aptitude", "ignorant that there were few minorities/women in this field", ending up with "physical activity", "absolute answers, answers are black or white", and finally "pay", with only one reference each (see Table 4.5 Interview Analysis - Themes and Frequencies, Question \#7-"Why did you go into this field?"). 
Table 4.5

Interview Analysis - Themes and Frequencies

Question \# 7 - Why did you go into this field?

Theme
\begin{tabular}{|l|l|l|l|}
\hline Role Model/Mentor & 8 & Exposure & 6 \\
\hline Sounded Interesting & 3 & Intellectual Challenge & 3 \\
\hline Job Security & 3 & $\begin{array}{l}\text { Absolute/answers are black } \\
\text { or white }\end{array}$ & 1 \\
\hline Physically active & 1 & Concrete results/products & 6 \\
\hline Aptitude & 3 & $\begin{array}{l}\text { "Ignorant" few minorities } \\
\text { in field }\end{array}$ & 3 \\
\hline Pay & 1 & & \\
\hline
\end{tabular}

* Frequencies total to more than 10 due to multiple themes raised.

Despite this variety of responses, there was one distinct experience that seemed to consistently be repeated throughout the different conversations; this was the effect of having had a strong role model and mentor. These role models were family members, teachers, and interested community members. They were interested in math, science, and technology, as well as the student and his or her development. Repeatedly I heard: "I had a very good high school [chemistry] teacher and that really got my interest in the subject", "he [high school teacher] made it easy for me." "I was blessed to have very good grammar school science teachers, who encouraged things like science (fair) participation."

Other survey participants found role models closer to home, "I remember doing little experiments when I was young. In hindsight they were kind of silly, but I remember 
doing experiments and my parents really encouraged it....As I got older, I became interested in the stars and why they are the way they are, and my parents sort of encouraged it along the way." Another stated, "There was a role model, a family member who was a doctor. I think all of us kind of look for people we can emulate their behavior". These mentors and role models seemed to make math and the sciences interesting, and provided the survey participants with support, encouragement and the opportunity to grow.

Some role models and mentors provided the participants with educational and career opportunities they might have missed.

The assistant to the math department at the public school had seen a flyer [for a Minorities Introduction to Engineering Program], that the department head had thrown away. She pulled it out, and made copies. Later she submitted the names of the interested students who were then able to participate in this program.

Others found their mentors providing them with more direct career guidance.

In college, a mathematics major, I was speaking to the head of the mathematics department, this was in the early 70's. He suggested that I major in computer science...I think this man probably knew [the future of computer science]...he called me into his office one day and asked me why I wasn't working in the [field]. I told him that all of the avenues I had pursued to get a job...didn't really pan out.....he put me in contact with a scientist who... was starting up a new lab, ...I called him up, came out for an interview. He was hired.

In addition to mentors and role models, exposure to the field they were ultimately to go in to also played an important role for many of the participants. 
I never been to a lab; I never met a scientist...I visited some labs and saw what kind of work went on in places like DuPont, and other chemical labs...and I decided that that was what I really would like to do.

Another informant said, "I spent the summer between my junior and senior high school at Lafayette, about two weeks... and they tried to give us an idea of what different types of engineers do, and they actually gave us calculators, you have to understand, this was 1975, and we were absolutely fascinated." A male scientist with less than five years in his field noted, "...we not only had our high school science fairs, we had the district level...the city level. There's the state science fair and from there there's even what they call the international one." For another, geographic proximity played a role, "I lived fairly close to Argonne National Laboratory and went there a lot during the summers." "Back while I was in elementary school, it started with scientific projects, experimentation, the fun of it...", said a relatively young engineer, who has been in the organization less than five years, "we grew-up in a household filled with science, math, engineering and things of that nature."

Despite there being some vivid recollections of how they became interested in the field, there were still some who didn't know. One person who had been in his field for longer than 16 years said, "I decided when I was seven that I was going to be a scientist, and it's not clear where that came from. It was clear then why I decided that, and it's not clear now."

- What have you enjoyed most about working in this field?

In response to this question there seemed to be a wider variety of answers. With a total of 14 identified themes there was a relatively evenly distributed response throughout. The most often cited theme ( 5 times) identifying what they most enjoyed about working in this field was that it was "result oriented and that there is a concrete conclusion." The other identified items were, in descending order, "problem solving and 
technical challenge", "creativity", "freedom to define project/work directions"(each with 3 responses), "making a difference", "job opportunities", "independent learning", "communication/sharing findings", and finally, mentioned only once, "link with personal values", "hands-on", "financial security", "fun/playing with toys", "orderly", and a "way of life/identity". A summary of these findings can be found in Table 4.6, Interview Analysis - Themes and Frequencies, Question \# 8 - "What have you enjoyed most about working in this field?"

Table 4.6

Interview Analysis - Themes and Frequencies

Question \# 8- What have you enjoved most about working in this field?

Theme
\begin{tabular}{|l|l|l|l|}
\hline $\begin{array}{l}\text { Problem solving/ Tech. } \\
\text { challenge }\end{array}$ & 3 & Creativity & 3 \\
\hline Making a difference & 2 & $\begin{array}{l}\text { Link with personal values/ } \\
\text { ethics }\end{array}$ & 1 \\
\hline Hands-On & 1 & Job opportunities & 2 \\
\hline Financial Security & 1 & Fun/Playing with "toys" & 1 \\
\hline $\begin{array}{l}\text { Freedom to define work } \\
\text { direction }\end{array}$ & 3 & Orderly & 1 \\
\hline Independent learning & 2 & Way of life/identity & 1 \\
\hline $\begin{array}{l}\text { Result oriented/ } \\
\text { concrete results }\end{array}$ & 5 & $\begin{array}{l}\text { Communication/ } \\
\text { sharing findings }\end{array}$ & 2 \\
\hline
\end{tabular}

* Frequencies total to more than 10 due to multiple themes raised. 
In this scientific and technical research and development environment results orientation and a desire for concrete conclusions was cited as most enjoyable about the field. Statements like," I like the experimentation [chemical] laboratory part, seeing a product, if you're doing research and development, ...you see your end results." This was voiced regardless of the field. "You have a problem, you identify it and you think out how it operates, then you figure out how to make it do what you want it to do, I kind of like that completeness." A physicist with between six to ten years in the field expressed it this way, "I think the most satisfying thing is sort of quenching this desire to understand why things are the way they are, more specifically, ...when you've done an experiment or if there is a question which the field [physics] is trying to answer and you come up with the answer, it makes you feel good...", A computer scientist, whose professional role provided him with a great deal of user interaction said, "I like computer science and the fact that my work is visible and a lot of people see the work I'm doing and use my product."

"Creativity" also appears on this list, and was expressed in phrases such as, "...[1] use my skills to come up with new ways of doing things...". One of the youngest participants in the study went so far as to give a highly contemporary example,

People for one think engineers are very analytical. You ask them one question or problem, they use the analytical approach. That's true, but I think if you allow it, or you kind of cultivate it, there's also a creative side to the engineer. So we look at things on TV or Star Trek, or things like that. There seems to be almost no limit to what you can do if you have the skills.

While a computer scientist who is well established in his career said, "Creativity, freedom, I think there's a lot of that, even though you are developing systems, or creating systems within certain boundaries, there's still quite a lot of room for creativity in how things are developed and presented." 
Though only specifically mentioned once during the interviews, there was a distinct sense of fun and enjoyment. It could be observed in the level of animation when they spoke about projects on which they've worked. In some cases it was almost the same level as when they talked about pleasurable experiences they've had with their families and in their personal life. It can also be seen in the use of the words "gadgets" and "toys" when used to describe the tools of their trade.

- What have you enioyed least about working in this field?

It was noteworthy that there were far fewer themes that came to light in response to identifying what satisfied the participants least about their field. In addition, there were only two clear areas that were frequently mentioned: the "impact of national politics" and "lack of control." Each of the other themes was only mentioned once: "routineness", "lack of job security", lack of ethics", "lack of respect for technical knowledge and expertise", "writing", "career obsession/driven by your desires", and "administrative versus technical duties conflict". A more detailed comparison can be found in Table 4.7 Interview Analysis - Themes and Frequencies Question \# 9 - "What have you enjoyed least about working in this field?" 
Table 4.7

Interview Analysis - Themes and Frequencies

Question \# 9 - What have you enjoyed least about working in this field?

Theme
\begin{tabular}{|l|l|l|l|}
\hline Routineness & 1 & Lack of job opportunity & 1 \\
\hline Impact of national politics & 4 & Lack of ethics & 1 \\
\hline $\begin{array}{l}\text { Lack respect of technical } \\
\text { expertise }\end{array}$ & 1 & Lack of control & 3 \\
\hline Writing & 1 & $\begin{array}{l}\text { Obsession/Driven by work } \\
\text { desires }\end{array}$ & 1 \\
\hline $\begin{array}{l}\text { Admin vs Tech duties } \\
\text { conflict }\end{array}$ & 1 & & \\
\hline
\end{tabular}

* Frequencies total to more than 10 due to multiple themes raised.

As a national laboratory, this organization's continued funding is totally dependent on decisions made in Washington, D.C. by different political institutions and individuals. In addition, the national scientific and technical focus is also directly impacted by governmental regulatory decisions which are usually beyond the control of the working researcher. Therefore it is not surprising that the "impact of national politics" was prominent in the participants' responses. Quotes such as, "What I don't like and didn't expect are the politics. The politicians really get their hands into the sciences." This theme was even echoed by the supervisors and managers who participated in this study. An engineer from this group voiced the following; "A lot of the science policy of this country, and all other countries, from what I understand, is really shaped by politicians. ... susceptibility and dependence on a somewhat unreliable political system which is probably our biggest headache." 
This frustration with the "impact of national politics" is closely tied to the "lack of control". A Ph.D. engineer voiced his frustration by saying, "The work itself is not a headache, it's a pleasure. Unfortunately the work does require funding and so if you live in uncertain times, like now, and stuff, it can become a roller coaster--ups and downs." The frustration was evident across the disciplines. A female computer scientist with more than 15 years in the field said, "A lot of times you see ways of solving a problem that you feel could really be effective. However, if the political atmosphere was there, and the funding isn't there, and the end user is not ready to accept change, it [the solution] can fall through the cracks and never happen or maybe not happen for a long time to come."

- What things satisfy you about your job here?

Despite being able to identify 13 distinct themes, it was interesting to note that there were no strong patterns apparent. (See Table 4.8 Interview Analysis - Themes and Frequencies Question \# 10 - "What things satisfy you about your job here?") What was found, with two references each, was: "control of work environment", "way of life and identity", "working on major projects", "financial support of research", "financial security", "continuous learning", "ability to do cutting edge research and development ", "usefulness of work and making a difference". Only one reference each was identified for: "working with people", "mutual respect", hands-on", "ability to spend time with family", and "creativity". 
Table 4.8

Interview Analysis - Themes and Frequencies

Question \# 10 - What things satisfy you about your job here?

Theme
\begin{tabular}{|l|l|l|l|}
\hline Way of life/identity & 2 & Working on major projects & 2 \\
\hline Working with people & 1 & Mutual respect & 1 \\
\hline $\begin{array}{l}\text { Financial support of } \\
\text { research }\end{array}$ & 2 & Hands-on & 1 \\
\hline $\begin{array}{l}\text { Ability to spend time with } \\
\text { family }\end{array}$ & 1 & $\begin{array}{l}\text { Control of work } \\
\text { environment }\end{array}$ & 3 \\
\hline Financial security/benefits & 2 & Continuous learning & 2 \\
\hline $\begin{array}{l}\text { Able to do cutting edge } \\
\text { R\&D }\end{array}$ & 2 & Creativity & 1 \\
\hline $\begin{array}{l}\text { Usefulness of work/making } \\
\text { a difference }\end{array}$ & 2 & & \\
\hline
\end{tabular}

* Frequencies total to more than 10 due to multiple themes raised.

Participants' satisfaction with their job as it related to control of their work environment was evident in statements such as: "I have pretty much the freedom to come and go as I please and still get my work done." A chemist with, six to ten years in the organization, echoed the sentiment that satisfaction with their job was related to their control of their work environment; "I guess the only true thing that I could say that I like is that the independence of doing research of at your own pace to get the final results..."

What was interesting, and was also noted in the survey question, was the reference of their career being their identity or way of life: "...I've moved away from engineering. I've moved into what could be, what I would now think of as software engineering. While I like software engineering, I'm a physicist who did some EE 
[electrical engineering] work..." While the disciplines were different, a Ph.D. engineer also seemed to share this view, "You know this [engineering] is something you not only do because it's your job, but it's a way of life, a life long career goal, so to speak."

- What things dissatisfy you about your job here?

In response to the question of what the participants enjoyed least about working in this field, there were nine identifiable themes. Though there were some similarities, as found in the responses of "routineness", "limited mobility/lack of job opportunity", "lack of respect for technical competence or ability", "lack of control of work assignments", and "writing", there were some new ones as well: "supervisory responsibilities", "internal politics", "research funding instability", and "competition". Once again there was a fairly equal distribution among these themes, each being used only once, with "lack of respect for technical competence or ability" and "supervisory responsibilities" each being noted twice, as shown in Table 4.9. 
Table 4.9

Interview Analysis - Themes and Frequencies

Question \# 11 - What things dissatisfy you about your job here?

Theme
\begin{tabular}{|l|c|l|l|}
\hline Routineness & 1 & Limited mobility & 1 \\
\hline $\begin{array}{l}\text { Lack respect of technical } \\
\text { expertise }\end{array}$ & 2 & Supervisory responsibility & 2 \\
\hline Internal politics & 1 & $\begin{array}{l}\text { Lack control of work } \\
\text { assignments }\end{array}$ & 1 \\
\hline Research funding instability & 1 & Having to write-up findings & 1 \\
\hline Competition & 1 & & \\
\hline
\end{tabular}

* Frequencies total to more than 10 due to multiple themes raised.

In general, "lack of respect for technical competence or ability" was not limited to non-technical people not respecting the achievements of scientists and engineers, as was voiced with respect to politicians and non-technical people making decisions for future research and funding. There was also a lack of respect felt from field to field within the technical community. This was extremely evident when a response to this question was "a lack of respect from other technical people." Also in response to this question, I began to glimpse feelings of resentment caused by this lack of respect:

As a black scientist...there always seems to be an; it's more true, I think, when I first came here as opposed to now; but there was always this underlying current. You can tell it in speaking to your colleagues, that you somehow got to this point as a gift. You didn't actually earn the right to be here, but someone sort of let you in the door. It's somewhat of an insult, and no one 
ever comes out and says that, or will say that to you, but you can tell it in the mannerisms sometimes.

In addition, the dissatisfaction resulting from "supervisory responsibilities" seemed to stem from the frustrations and inconsistencies of working with people. "You have to supervise this person and try to motivate them to do well and repeat things more than you think you had to repeat them and still may not pan out." Another relatively new supervisor agreed, "Personnel Management, they throw you in the deep end and you hope to out swim the sharks, so that is difficult and more times than not, not pleasant."

- Do there seem to be different satisfiers for other colleagues who are white?

There were few perceived differences in satisfiers from other colleagues who are white, and only two were mentioned. (See Table 4.10, Interview Analysis - Code Words and Frequencies Question \# 12 - "Do there seem to be different satisfiers for other colleagues who are white?") During the interviews, all of the participants expressed a significant sense that there was an inequity of treatment in the achievement of levels of satisfaction, between African-Americans and their white colleagues.

Table 4.10

Interview Analysis - Themes and Frequencies

Question \# 12 - Do there seem to be different satisfiers for other colleagues

who are white?

\begin{tabular}{|c|c|c|c|}
\hline Theme & $\mathrm{F}$ & Theme & $\mathrm{F}$ \\
\hline $\begin{array}{l}\text { White co-workers seem to } \\
\text { lack the need of a sense of } \\
\text { community }\end{array}$ & 1 & $\begin{array}{l}\text { Everyone is the same/only } \\
\text { individuals differ }\end{array}$ & 2 \\
\hline
\end{tabular}


Of all of the survey questions this one elicited the fewest direct responses, yet the responded it yielded indicated that this area of differences touched on a sensitive nerve that ran close to the surface. Frequently the participants responded to this question with examples of differences in treatment or opportunity. On several occasions anecdotal stories were share as to how white peers with similar qualifications had been promoted ahead of them.

In direct response to this question, the first difference specifically noted was that "white co-workers seemed to lack the need of a sense of community" or to give back to their community, in this case the African-American community. Many of the participants in the study talked of their sense of community and their need to give back to the black community and that this was a feeling they had which was different from white colleagues. In their conversations many of the survey participants used phrases like "our people" and "my community" expressing their sense of belonging to a greater cultural group. One woman said, "I think that for minorities, African-Americans, you have a double responsibility of giving back, not just to your country, but to your [AfricanAmerican] community." This general sense of the need to give back was best expressed by one of the participants, who himself had earned a Ph.D., "I think it's somewhat of a duty for anyone that gets an advanced degree, and this is my own belief, is that it's important to sort of pass on your knowledge of what you are to someone else, to coming generations."

One woman spoke of her concern that she had not taken the time to give back, or to reach back to help others coming up behind. Her tone of voice could even be described as apologetic. Another participant spoke to her desire to improve the lives of minorities in a more general grouping as being a motivating factor behind their field selection of environmental engineering, 
..I like that I'm making a difference for minorities because many of them don't have the money to move out of the neighborhoods. So they're the ones living next to land fills, they're the ones living next to industrial areas that are polluted, they're the ones that are going to have the increased health risks...I feel like I'm making a difference.

Another participant with a Ph.D. and less than five years work experience also wanted to make a contribution,

Now since I'm here, it's important for me to also be able to reach back to other people I know [black]...and extend them the same opportunity that was extended to me. So, that's what I mean by a communal way of doing things as you rise through the ranks. Not just going out and getting program monies so that our program budget is huge, and things like that, but the people component; you have to make sure that's intact.

Later on in the conversation with the same person, it was again said, "I'd like to sort of maintain that type of connection. No matter how hard, I could reach back and help students get through school, and some of the things I did. That would be a lot 'cause I know I struggled, at times going through school."

The desire on the part of the study participants to contribute was not solely philosophical, but practical. Several of the participants in the study host AfricanAmerican students for the summer, in their homes as well as their laboratory's, providing them valuable exposure and work experience as well as role models and mentors. "I always tell students, when I go and speak to students, minority students, is that rocket science is not really 'rocket science.' People want you to think it is, but it's really not that hard to do."

Despite their initial feelings that there was a difference from their white colleagues, that "white co-workers seemed to lack the need of a sense of community" or 
to give back to their community, in this case the African-American community, or the study participants' need to give back to the black community; they also felt that what was necessary for job satisfaction was unique to the individual regardless of race:

You find rewards in different areas; I mean some people think of rewards as monetary... I mean it takes different forms, and everyone's different. But I think in general, it's mainly the same. People want to go to work and feel that they're confident in doing their job, and do a good job, and feel good about that. So, I don't think there's any difference there.

\section{- How would you define success for yourself?}

The definition of success yielded 14 themes with five of them more frequently mentioned than the others. These four: "achieving dynamic goals", "success is a process", "control of work projects", "personal satisfaction and comfortable with self", and "giving back to the community", were mentioned multiple times. Each of the remaining nine were only mentioned once or twice: "career advancement", "getting published", "ability to care for and support family", "passion for work", "educational achievement", "peace of mind", "money to do the things I want", making professional contributions", "helping others achieve their goals" (see Table 4.11, Interview Analysis Code Words and Frequencies, Question \# 13 - "How would you define success for yourself?"). 
Table 4.11

Interview Analysis - Themes and Frequencies

Question \# 13- How would you define success for yourself?

Theme
\begin{tabular}{|l|l|l|l|}
\hline Career advancement & 1 & Control of work projects & 4 \\
\hline Getting published & 1 & $\begin{array}{l}\text { Personal } \\
\text { satisfaction/comfortable } \\
\text { with self }\end{array}$ & 4 \\
\hline $\begin{array}{l}\text { Able to care for \& support } \\
\text { family }\end{array}$ & 2 & Success is a process & 4 \\
\hline Achieving dynamic goals & 5 & Passion for work & 1 \\
\hline $\begin{array}{l}\text { Giving back to the } \\
\text { community }\end{array}$ & 4 & Educational Achievement & 2 \\
\hline Peace of mind & 1 & $\begin{array}{l}\text { Money to do the things I } \\
\text { want }\end{array}$ & 1 \\
\hline $\begin{array}{l}\text { Making professional } \\
\text { contributions }\end{array}$ & 1 & $\begin{array}{l}\text { Helping others achieve their } \\
\text { goals }\end{array}$ & 1 \\
\hline
\end{tabular}

* Frequencies total to more than 10 due to multiple themes raised.

It could be safe to say that to the participants in this study success is a process with dynamic goals. "Success is a dynamic process." A computer scientist, with more than 16 years in the field expressed her view as, "I see success as something you never really achieve. I don't think I would ever think of myself as being successful for fear of being complacent." She went on to say, "The reward is actually in the trying, in moving toward the goal, in going through the process." An engineer, also with more than 16 years in his field, described success this way;

What you got to do is, you got to aim for the stars knowing you only want to go to the moon. See, because that way, even if you miss the stars, you end up on 
Mars, Jupiter or the Moon at least, so that's kind of how you do it. You set up some goals, some of them may be quite lofty and stuff, but you have enough flexibility and stick-to-it-tiveness to realize that if you don't get your loftiest one, you'll still get a hell of a lot along the way and that's really what you're after. For me success has always been a moving border...

As with the responses to the questions on field and job satisfaction here too the ability to control the direction of one's work is important. Success to this group included "...a chance to be involved in all the conversations about what direction the program will go."

- Do you feel that you have been successful?

As a group there was a feeling that they were successful or in a successful process. This can be seen in the themes identified in Table 4.12, Interview Analysis Themes and Frequencies, Question \#14 - "Do you feel that you have been successful?" Of all of the participants, only one person felt unsuccessful and was "stuck on square one". Despite this expressed sentiment, the participant indicated that some success had been experienced. 
Table 4.12

Interview Analysis - Themes and Frequencies

Question \#14 - Do you feel that you have been successful?

Theme
\begin{tabular}{|l|l|l|l|}
\hline Not at all: & F & Theme & F \\
\hline Stuck on square one & 1 & gemewhat: & 3 \\
\hline & & coming into own style & 1 \\
\hline $\begin{array}{l}\text { Successful: } \\
\text { I've been very successful }\end{array}$ & 3 & growing & 1 \\
\hline Enjoy my job & 1 & success = complaisance & 2 \\
\hline $\begin{array}{l}\text { Achieving milestones on } \\
\text { road to success }\end{array}$ & 1 & & \\
\hline
\end{tabular}

* Frequencies total to more than 10 due to multiple themes raised.

In as much as the group of participants had earlier expressed their attitude that success was a process, it was not surprising that they also indicated that they were somewhat successful with statements such as, "I've been very successful." "I feel that I'm successful..." "For me success is being happy...and I have that. I believe I am, and I know I'm successful because everything that you set aside and set a goal for myself, I achieved from fourth grade to now."

In light of the participants' attitude toward success being a process, it would be logical and appropriate for the participants to indicate, as they did, that they were "growing", "making progress" and coming into their own style. Regardless of the number of years in their fields, or in the organization, this process oriented approach of "achieving milestones" seemed to provide the group with a distinctly positive attitude 
towards their work and the attitude that progress was being made and that the ultimate achievement of a final goal called "success would lead to complacency." 


\section{Chapter 5}

\section{SUMMARY AND CONCLUSIONS}

\section{$\underline{\text { Review of the Problem }}$}

In recent years we have witnessed an increasing shift in our economic base to "high tech," technical and scientific research and development. No longer are we manufacturers to the world; as a nation we have become designers and developers with more and more of our jobs requiring higher and higher levels of education and skills. These types of jobs are the future for U. S. employees. As the demographic figures have indicated, these jobs will also be the future for African-Americans.

The institution in which this study took place, as well as others, has begun to focus on the development of their employees' awareness of the value of a culturally diverse work force. In looking at, and valuing, these differences, do the components necessary for job satisfaction vary from culture to culture? To determine this, the elements necessary for job satisfaction in a culture must be identified before any comparison can take place. This study was an attempt to begin to identify the elements necessary for job satisfaction for African-Americans in a technical and scientific research and development environment.

\section{Discussion of the findings}

In reviewing the findings of this study it was evident that the sample size and use of a single organization may have had a definite impact on the perceptions the participants had of their work world. Despite yielding interesting observations, there were no strong identified trends that would indicate potential satisfiers unique to the 
African-American culture. Yet the findings did provide a valuable insight into the perceived realities of this particular environment.

In order to begin to understand the findings of this study, first it was necessary to look at job satisfaction. Maslow felt that there was a hierarchy of five needs which must be met to experience job satisfaction. Beginning with the physiological (basic), and progressing in an orderly fashion through, safety and security, the need for belonging, ego status and finally ending with self actualization (Burke, 1982), a person finds first extrinsic, and ultimately, intrinsic rewards.

Throughout the interviews there were few references to the need for extrinsic rewards. For the question, "Why did you go into this field?" there was only one reference to an extrinsic reward, "pay". Of the other questions in the survey, only the question asking for their definition of success yielded any references to extrinsic rewards. These were isolated and only mentioned once each: "career advancement", "getting published", and "money to do the things I want". In terms of safety and security, there were concerns voiced about the impact of national politics on research funding and financial security. As for the need for belonging, their identification with their career ("way of life/identity") would group them together with others with like identities, regardless of ethnicity. The ego status need was met by publishing and sharing findings with others, while examples of self actualization could be found in themes such as: "link with personal values/ethics", "personal satisfaction/comfortable with self", and "peace of mind".

By far the most frequently noted responses to the survey's questions could be considered intrinsic in nature. Intrinsic rewards or satisfiers are far more difficult to group in that they are more individual, and more closely tied to the individual's values and belief system, unlike extrinsic rewards that are controlled by the field or specific job. According to Hackman and Oldham (1975), there are three key psychological states that affect an individual's job satisfaction: (1) experienced meaningfulness, (2) experienced 
responsibility, and (3) knowledge of results. In addition, for a job to contribute to these three key psychological states there are five criteria that must be met: skill variety, task identity, task significance, autonomy, and feedback.

The first of Hackman and Oldham's three key psychological states, "experienced meaningfulness" was evident in the frequency and variety of ways it was identified. Themes such as: "problem solving/technical challenge", "creativity", "personal satisfaction/comfortable with self", and "achieving dynamic goals", were used more than twice as often as others in response to the questions. Almost as frequently used were themes that demonstrated the need and desirability of Hackman and Oldham's experienced responsibility: "independent learning", "control of work environment", and "control of work projects". Finally, Hackman and Oldham's knowledge of results was also evident in the responses: "results oriented/concrete results", "usefulness of work", and "communication/sharing findings".

To the study participants, their particular field is a "way of life" and their "identity". How they viewed life and made decisions, was guided by their being a "scientist". They took their identity from the tasks they perform every day, and not from the purpose of the greater enterprise. They have defined themselves within the greater system, over which we have little control, within the boundaries and the definition of their roles over which we do exercise some control, defining themselves by their tasks or roles: engineers, computer scientists, chemists, biologists and physicists. Without this they could lose a critical portion of their identity (Senge, 1990). In defining themselves as biologists, chemists, computer scientists, engineers and physicists, they are identifying themselves not just within the limits of this organization but within a larger community; identifying themselves as intellectuals gaining their identity and reinforcement from other researchers outside this organization. 
Work related attitudes of employees have been analyzed extensively, and the literature shows that among all occupations, professionals are the most satisfied (Trankina, 1991). This was true of the participants in this study. In a recent study Trankina (1991) found that fifty percent of scientists from a sample representation of the entire U.S. population reported dissatisfaction in their work, and that the variables of importance to scientists were (most important to least): (1) important meaningful work, (2) income, (3) chances for advancement, (4) short hours, (5) security. These variables were also evident in this study, but not necessarily to the same extent. As with Trankina's study, important and meaningful work was cited by this study's participants as being an important prerequisite for job satisfaction. Participants used words and themes such as: "technical challenge", "making a difference", "working on major projects", "ability to do cutting-edge development/research", and "achieving dynamic goals" that not only confirmed to Trankina's work, but Maslow's being self actualizing in nature. While income and security didn't play as significant a role as a variable indicator of job satisfaction to the participants' in this study as they did in Trankina's, this could in part be the result that all were employed in relatively secure government funded positions.

It became clear that the research participants felt that there was no real difference in job satisfiers from their other colleagues who are white. Of those patterns of job satisfiers that were expressed, none of them were seemingly unique to African-Americans in this type of environment. In further support of this observation was the participants' response to the question: "Do there seem to be different satisfiers for other colleagues who are white?" This question yielded two impressions: that white co-workers seemed to lack the need for a sense of community, and that everyone had basically the same satisfiers.

The dominant Anglo culture of the United States, can best be described as "hyperindividualistic, almost narcissistic in nature." We have historically recognized the gains 
of the individual and prized individuality and the loner. As a culture we talk about our support of "community" yet do we truly know what it is or believe in it. Even today we recognize individuals and not the community that they are a part of. When we talk of success in the software industry, people talk of Bill Gates, yet his success was the result of a collective effort. We talk of the individual astronauts, forgetting the teams that made their trip possible. Even at an early age individuality is rewarded in school. Grades are not given to groups, nor are there rewards for ensuring the success of the class. Each student is pitted against the other for an individual reward and recognition. This is not limited to grade school. When universities have asked industry what they have wanted in graduates, industry has said "teamplayers and team skills." To this the univeristies responded, "ok, as soon as you start recruiting for team skills instead of GPA...we'll do it!"

Yet for the participants in this study, there was a need for a sense of community. Their identity was drawn from the communities in which they grew-up, and their racial and cultural identity. This was evident throughout the interviews as several of the participants bemoaned the competitive nature of research and development and how it fostered the need for isolation and strong competitive egos and not group interaction. The participants desire to be a part of a community was further demonstrated in their allocation of time and resources to the cultural group to which they felt a part.

An unexpected finding was the strong perception that despite this seeming lack of perceived differences in satisfiers, there was a significant sense that there was inequity in treatment. Participants frequently took advantage of this question to energetically voice this concern, quite often becoming more animated than they had previously been. Examples were given where peers, who were less capable had been promoted, or the unspoken perception that by virtue of race they had been hired, not because of their qualifications. 
In reviewing the research, there were two areas that were possibly unique for non-dominant culture members, in this case African-Americans, and therefore noteworthy: (1) the impact of not having had perceived social or cultural limits as to what they could do as a career, and (2) an expressed sense of community (African-American) and the need to give back to it.

Despite all of the advances that the United States has made, its dominant culture is still one that categorizes and places labels and limitations on select sub groups within the overall society. This experience is not limited to African-Americans, but has been the reality for women, Hispanics, Asians, American Indians, Gays, Jews, Catholics, the Irish, the Italians, the disabled and smokers, to name a few. This discrimination was a very real part of the African-American experience with laws in many states prohibiting full participation in many aspects of life, that are today taken for granted. There were prejudicial attitudes presenting obstacles where laws didn't exist. It was this world, that of the 1950's and '60's, that shaped the lives of many of the survey participants. As a result, science and technology were not fields in which there were a large number of role models nor were African-Americans encouraged to pursue careers in that arena. It is interesting that several of the survey's participants specifically cited their "ignorance" of the fact that there were so few minorities in these fields or that this was something that was not a career option for them. Was this "ignorance" the result of adult efforts to protect them, or was this a possibly unconscious decision they made as a defense against possible challenges to their career selection? Regardless of any theories as to the cause, the reality was that these individuals, as the result of their "ignorance", entered careers in the fields of science and technology, where there were, and still remain today, few African-Americans.

The other interesting finding was the expressed sense of being a part of the greater African-American community and the need to give back to others and more specifically 
help others in their climb up the technical and professional ladder. Expressed in a variety of ways, each of the participants believed they are culturally and racially connected. This connection transcends professional field, geography, or nationality. There was an expressed sense of community which seemed to define itself along old lines of racial division, which was inclusive of a variety of black sub-cultures, and drawn along racial identity lines. From "giving back to the community" to addressing environmental and socio-economic ills, there was a desire to contribute to a lasting change. Theirs was not a concern that was voiced for a larger more inclusive community that crossed racial boundaries, but for their own. When some spoke, there was a passion and conviction in their words that gave energy to their ideals and efforts, while others spoke softly, almost with a tone of guilt for the feeling of not having done enough.

\section{Conclusions}

The purpose of this study was to begin to develop an answer to the question, "What elements are necessary, in the work environment, for African-Americans to experience job satisfaction?" Ultimately it has left more questions unanswered than it answered.

As one of the first studies to focus on African-Americans working in a high-tech, scientific and technical research environment, the study has just begun to identify what might be individual satisfiers and initial trends.

The initial concerns as to the limitations of the study met mixed responses. On the impact of cultural differences within the race, this seemed to have little effect on the process or the findings. There was a distinct feeling of inclusion based more on racial identity, than cultural heritage. As to concerns regarding the impact of the current work environment on the views of the survey participants, the work environment did have an 
impact. This was evident in their concern about the impact of national politics and political agendas on the realities of working in their fields, as well as on their jobs.

The interview questions that were designed to be open ended in order to encourage the participants to expand on their thoughts within its loose framework were effective. They provided a framework for exploration and encouraged the sharing of personal experiences and stories. Future research should separate the questions more distinctly into addressing the individual's exposure to and entrance into the field, from actual work experiences and evaluations.

The limited scope of this study proved to be an impediment in identifying what might be significant patterns. Further research is necessary. A larger group, as well as a broader sampling of African-American scientific and technical professionals, would form a more diverse corporate pool that would begin to confirm or challenge the initial trends observed. Finally, there seemed to be a distinct difference in perceptions and experiences between those participants who were in what would be considered technical disciplines and those that are considered scientific. Using this as an additional control variable could provide additional insight.

An additional result of the study was the significance that mentors and role models as well as early exposure, had on the selection of the participants' career fields. Future research into this could provide useful information in the effort to increase the number of African-Americans, as well as other under represented groups, in the sciences and technology.

The National Science Foundation Predicts that there will be a shortage of 400,000 scientists in the USA by the year 2006 (Holden, 1989). Knowledge of work related attitudes of scientists could help provide recommendations for attracting more people to the field in the future as well as provide a basis for immediate improvements in the 
management of currently employed scientists in academia, industry, and government settings (Trankina, 1991).

In addition, the lack of empirical data concerning job satisfaction in high tech industry is a glaring omission in view of high technology's growing economic significance and its leadership in the development of new kinds of organizations and work behavior (Gamst \& Otten, 1992). In the past ten years, the population of the United States has continued to grow at a rapid rate with a $6 \%$ increase in the population of those individuals identified as Caucasian. At the same time, among those individuals of color, population growth was even greater African-American, 13.2\%; American Indian, 37.9\%; Asian or Pacific Islander, 107.8\%; Hispanic, 53\% and Other 45\%. With this continued growth trend, there will be over 16.5 million African-Americans employed in the civilian labor force by the year 2000. (U.S. Department of Commerce Economics and Statistics Administration Bureau of the Census, 1992) According to the literature, there is a strong relationship between job satisfaction and industrial, social and economic issues including worker and corporate productivity, worker behaviors, and quality of work life. Improvements in job satisfaction could yield important advances in a variety of other areas, all to the benefit of the nation, its corporations and its citizen employees. In order to achieve this, an answer must be found to the original question raised in this study: "Are the elements necessary for job satisfaction applicable and valid for each of our nation's cultures and ethnic groups?" 


\section{References:}

Babbie, E. (1992). The Practice of Social Research, Sixth Edition. Belmont, CA: Wadsworth Publishing Company

Begley, S. (1995, February 13) Three is not enough: Surprising new lessons from the controversial science of race. Newsweek, 67-69.

Bramlett-Solomon, S. (1992). Predictors of job satisfaction among black journalists. Journalism Quarterly, 69 (3), 703-712.

Buckley, M. R., Carraher, S. M. \& Cote, J. (1992). Measurement issues concerning the use of inventories of job satisfaction. Educational and Psychological Measurement, 52, 529-543.

Burke, W. W. (1982) Organizaiton development: Principles and practices. Boston: Little, Brown and Company.

Cose, E. (1995, February 13) One drop of bloody history. Newsweek, 70-72.

Cosner, L.A. \& Rosenberg, B. (eds.). (1965). Sociological theory: A book of readings. New York: Macmillan.

Dawis, R.V., \& Lofquist, L.H. (1984). A pshchological theory of work adjustment. Minneapolis: University of Minnesota Press.

Decker, P. J. \& Borgen, F. H. (1993). Dimentions of work appraisal: Stress, strain, coping, job satisfaction, and negative affectivity. Journal of Counseling Psychology, 40 (4), 470-478.

Denzin, N.K. \& Lincoln, Y.S. (ed.) (1994) Handbook of qualitative research. Thousand Oaks, CA: SAGE Publications.

Diener, E. (1984). Subjective well-being. Psychological Bulletin, 95, 542-575.

Dye, T.R. and Renick, J. (1981) Political power and city jobs: Determinants of minority employment. Social Science Quarterly, 62,475-486.

Fontana, A. \& Frey, J. H. (1994) Interviewing: The art of science. InN.K Denzin \& Y.S. Lincoln (Eds.), Handbook of Qualitative Research (pp.361-376). Thousand Oaks, CA: SAGE Publications.

Frankel, M. S. (1993, November), Multicultural science: Minority scholars bring key perspectives to research and policy issues. The Chronicle of Higher Education, $\mathrm{p}$. B3.

Freud, S. (1961). Civilization and its discontents (J. Strachey, Trans.). New York: Norton. (Original work published 1931)

Gamst, G. \& Otten, C. M. (1992). Job satisfaction in high technology and traditional industry: Is there a difference? The Psychological Record, 42, 413-425. 
Herzberg, F. (1966) Work and the nature of man. New York: Thomas Y. Crowell Publishers.

Holden, C. (1989). Wanted: 675,000 future scientists and engineers. Science, 244, 15361537.

Hudson Institute. (1987) Workforce 2000: Work and workers for the 21st century. Indianapolis: Hudson Institute.

Johnston, W.B. (1988) Civil Service 2000. U.S. Office of Personnel Management

Judge, T. A.\& Watanabe, S. (1994). Individual differences in the nature of the relationship between job and life satisfaction. Journal of Occupational and Organizational Psychology, 67, 101-107.

Judge, T. A.\& Watanabe, S. (1993). Another look at job satisfaction-life satisfaction relationship. Journal of Applied Psychology, 78 (6), 939-948.

Kanter, R. M. (1977) Men and women of the corporation. New York: Basic Books, Inc.

Lawrence Livermore National Laboratory (1994) Affirmative action plan for women, minorities, individuals with disabilities and covered veterans. Livermore, CA: University of California. (UCRL-AR-111638-94)

Leigh, J. W. (1976) (Guidelines to be used by social workers working with racial minority populations) unpublished

Lincoln, J.R. and Kallenberg, A. (1985) Work organization and workforce commitment: A study of employees in the U.S. and Japan. American Sociological Review, $\underline{50}$, 738-750.

Mladenka, K.R. (1989) Blacks and Hispanics in urban politics. American Political Science Review, 83 (1), 165-191.

Miller, D. C. (1991) Handbook of research design and social measurement. London: Sage Publications.

Morganthau, T. (1995, February 13) What color is black? Newsweek, 63-65.

National Science Foundation. (1971) Science and engineering doctorates: supply and utilization. Washington, DC: National Science Foundation

Perry, L. S. (1992). Effects of inequity on job satisfaction and self-evaluation in a national sample of African-American workers. The Journal of Social Psychology, 133 (4), 565-573.

Ploski, H. A. and Williams, J. (1989) The Negro Almanac: A reference work on the African American. Detroit: Gale Research Inc. 
Rentisch, J. R. \& Steel, R. P. (1992) Construct and concurrent validation of the Andrews and Withey Job Satisfaction Questionaire. Educational Psychological Measurement, 52, 357-367.

Rubaii-Barrett, N. \& Beck, A. C. (1993). Minorities in the majority: Implications for managing cultural diversity. Public Personnel Management, 22 (4), 503-521.

Senge, P. M. (1990) The fifth discipline: The art and practice of the learning organization. New York: Doubleday Currency.

Skinner, B.F. (1969) Contingencies of reincorcement. Englewood Cliffs, NJ: Prentice Hall, Inc.

Soukhanov, A.H. \& Ellis, K. (ed.) (1984). Webster's II: New Riverside University DIctionary Boston, MA: Riverside Publishing Co., Houghton Mifflin Co.

Stein, L. (1986) Representative local government: Minorities in the municipal workforce. Journal of Politics, 48, 694-713.

Tait, M., Padgett, M.Y. \& Baldwin, T.T. (1989). Job and life satisfaction: A reexamination of the strength of the relationship and gender effects as a function of the date of the study. Journal of Applied Psychology, 74, 502-507.

Tausky, C. (1992). Work is desirable/loathsome: Marx versus Freud. Work and occupations, 19 (1), 3-17.

Trankina, M. L. (1991). Psychology of the scientist:LXIV, work-related attitudes of U.S. scientists. Psychological Reports, 69, 443-450.

Tuch, S. A. \& Martin, J. K. (1991). Race in the workplace: Black/white differences in the source of job satisfaction. The Sociological Quarterly, 32 (1), 103-116.

U.S. Department of Commerce Economics and Statistics Administration Bureau of the Census. Statistical abstract of the United States, 1992: The national data book. (1992) Washington, D.C.: U.S. Department of Commerce Economics and Statistics Administration Bureau of the Census

U.S. Department of Energy. (1994) Strategic plan for diversity.. Washington, D.C.: U.S. Department of Energy unpublished

U.S. Department of Energy, Assistant Secretary, Human Resources and Administration, Office of Professional and Technical Training and Development(1994). Valuing employee diversity. (DOE/HR-0055) Washington, D.C.: U.S. Department of Energy.

U.S. Department of Labor. (May 1993) Federal contract compliance manual. Washington, D.C.: Employment Standards Administration, Office of Federal Contract Compliance.

Warren, C.A.B. (1988) Gender issues in field research. Newbury Park, CA: SAGE Publications. 


\section{$\underline{\text { Appendix A }}$}

\section{Beginning Interview Questions}

\section{ID \#}

1)

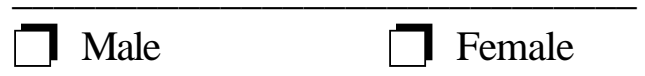

2) D.O.B. (month/date/year):

3) Job Classification/Title:

4) Education (High Degree):

5) Years in the organization:

6) Years in the field:

7) Why did you go into ... Field...?

8) What have you enjoyed most about working in this field?

9) What have you enjoyed least about working in this field?

10) What things satisfy you about your job here?

11) What things dissatisfy you about your job here?

12) Do there seem to be different satisfiers for other colleagues who are white?

13) How would you define success for yourself?

14) Do you feel that you have been successful

15) Later on, I'd like to clarify some of these issues.

What's a good time to contact you?

$\boldsymbol{\nabla}$ Thank you for taking the time to talk with me and if you are interested I can send you a brief synopsis of my findings. $\square$ YES

NOTE:

- $\quad$ Encourage the subject to relay stories / anecdotes of what has happened, or experiences they have had, that demonstrate the issues around being an African-American employee at the Lab. 


\section{$\underline{\text { Appendix B }}$}

\section{Invitation to Participate in the Study}

\section{Month/Date/Year}

\section{Dear Colleague:}

I am writing to invite you to participate in a research study that will be part of my thesis for the completion of my Masters in Human Resources and Organization Development, at the University of San Francisco. The topic of my study is "A Qualitative Study of African-American Job Satisfaction in a Scientific and Technical Research Environment." As an African-American and an employee here at the Lab, this study is of special interest to me. The results of this study will add a new dimension to work that has been done on job satisfaction in an increasingly diverse workforce.

This letter is being sent to approximately 58 full time career employees in the 200 SeriesJob Classification, who have identified themselves as being African-American. Of those of you who indicate a willingness to participate in the study, a representative sample group of about eight to ten individuals will be selected to be interviewed. The interview questions will focus on the uniqueness of being an African-American and the optimal work environment for us to experience job satisfaction. The interview will take about one hour and will be scheduled at a time and location for your convenience and to ensure your anonymity.

If you are interested in participating in this study, please take a few minutes to complete the attached Interest Indication Response Form and return it to me in the enclosed envelope by $\underline{\boldsymbol{a b}} / \boldsymbol{c d} / \mathbf{9 5}$ You will be notified within a week whether you have been selected and to schedule an interview.

Thank you for your participation in this research study. The results of this study will be available from me by request. Please feel free to contact me with any questions you might have. I can be reached at extension 2-9333, and by either QuickMail or e-mail (krossa1@llnl.gov).

Sincerely,

Cheryl D. Krossa

Affirmative Action Planning Coordinator

Affirmative Action and Diversity Program 


\section{Appendix C}

\section{Interest Indication Response Form}

If you are interested in possibly participating in this study, please provide with the following information. When you are done, return this form using the preaddressed envelope provided:

Name:

D.O.B. (month/date/year)

L-Code: Extension/Pager:

Job Classification \#: Job Classification Title:

- Please check all appropriate boxes.

Gender: $\square$ Female

Male

Education:

BA/BS $\square$ MA/MS

PhD

Undetermined (ie., JD, MD)

How many years have you worked in this field/profession?
$\square<5 \square 6-10$
11 - 15
16 - 20
$21-25$
$26>$

How many years have you worked at the Lab?

$\square<5 \square 6-10 \square 11-15 \square 16-20 \square 21-25 \square 26>$ 


\section{Appendix D}

\section{Consent To Be A Research Subject}

A. PURPOSE AND BACKGROUND

Cheryl D. Krossa as part of the requirements for the completion of a Masters in Human Resources and Organization Development, in the College of Professional Studies at the University of San Francisco, is conducting a qualitative study on African-American job satisfaction in a scientific/technical research environment, which I am being asked to participate in.

\section{B. PROCEDURES}

If I agree to be in the study, the following will occur:

1. I will be asked to respond to and discuss a series of interview questions related to areas which might affect job satisfaction.

2. Audio tapes will be made of the interview and subsequent discussions

This will take place at a time and location, which is mutually agreed upon, and that will, facilitate the interview process, ensure enhanced confidentiality and convenience. The total time needed should be approximately one (1) hour.

\section{RISKS/DISCOMFORTS}

In order to insure confidentiality each subject will be given an identification code which will be held separate from all other identifying data such as name, gender, age, education, profession, and years of service. During the interview notes will be taken and the conversation will be tape recorded. The notes as well as the tape will be identified by the pre-assigned identification code. Within a week of the interview, the tape will be transcribed. In order to complete the transcription in a timely manner it may be necessary to hire a typist from ourside the organization. The tape given to this individual will only be identified by its identification code. When completed both the tape and the transcription will be returned to the researcher.

The tapes will be retained, in a locked repository (vault) until the completion of the study, at which time they will be destroyed. Only the Principle and Co-investigators will have access to the tapes or transcripts.

\section{BENEFITS}

There will be no direct benefit to me from participating in this study. The anticipated benefit of this study is a better understanding of job satisfaction for AfricanAmericans.

\section{E. ALTERNATIVES}

I am free to choose not to participate in this study.

\section{F. COSTS}

There will be no cost to me as a result of taking part in this study.

\section{G. REIMBURSEMENT}

I will receive no monetary compensation as a result of taking part in this study.

\section{H. QUESTIONS}

I have talked to Cheryl Krossa about this study and have had any questions I may have had answered. If I have any further questions about the study, I may call her at (510) 422-9333. 
Consent to be a Research Subject

Page 2

If I have any questions or comments about participation in this study, I should first talk with the investigator. If for some reason, I do not wish to do this, I may contact IRBPHS, which is concerned with protection of volunteers in research projects. I may reach the IRBPHS office between 8:00AM and 5:00PM, Monday to Friday, by calling (415) 666-2416, or by writing to the IRBPHS, Psychology Department, University of San Francisco, 2130 Fulton Street, San Francisco CA 94117-1080.

\section{CONSENT}

I have been given a copy of this consent form to keep.

PARTICIPATION IN RESEARCH IS VOLUNTARY, I am free to decline to be in this study or to withdraw from it at any point.

Date
Cheryl D. Krossa, Researcher

Subject's Signature 


\section{Appendix E}

\section{Interview Analysis (IA) Form}

Question \# 7 - Why did you fo into this field?

Themes:
\begin{tabular}{|l|l|l|l|}
\hline & & & \\
\hline & & & \\
\hline & & & \\
\hline & & & \\
\hline & & & \\
\hline & & & \\
\hline
\end{tabular}

Question \# 8 - What have you enjoyed most about working in this field?

\begin{tabular}{|l|l|l|l|} 
Themes: & F & Themes & \\
\hline & & & \\
\hline & & & \\
\hline & & & \\
\hline & & & \\
\hline & & & \\
\hline
\end{tabular}

$\mathrm{F}=$ Frequency 


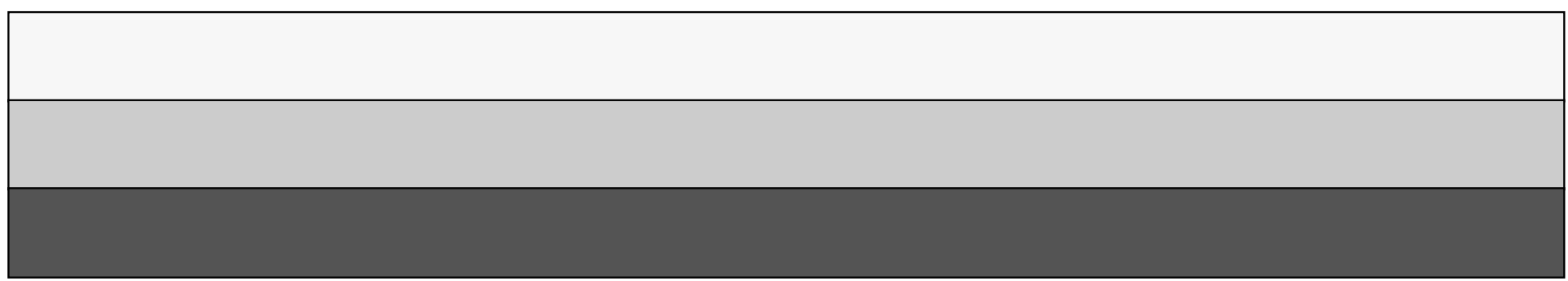

